This manuscript was submitted to Earth Surface Processes and Landforms. This version was resubmitted after peer-review and at the time this preprint was uploaded, it had not been formally accepted. Subsequent versions of the manuscript may differ slightly. The final, published version is available at https://doi.org/10.1002/esp.5059. 


\title{
Mechanisms for avulsion on alluvial fans: insights from high-frequency topographic data
}

\author{
Anya Leenman* and Brett Eaton \\ Department of Geography, University of British Columbia, 1984 West Mall, \\ Vancouver BC V6T1Z2, Canada
}

\begin{abstract}
Avulsion is a key process in building alluvial fans, but it is also a formidable natural hazard. Based on laboratory experiments monitored with novel high-frequency photogrammetry, we present a new model for avulsion on widely graded gravel fans. Previous experimental studies of alluvial fans have suggested that avulsion occurs in a periodic autogenic cycle, that is thought to be mediated by the gradient of the fan and fan-channel. However, these studies measured gradients at low spatial or temporal resolutions, which capture temporally or spatially averaged topographic evolution. Here, we present high-resolution $(1 \mathrm{~mm})$, highfrequency (1-minute) topographic data and orthophotos from an alluvial fan experiment. Avulsions in the experiment were rapid and, in contrast to some previous experimental studies, avulsion occurrence was aperiodic. Moreover, we found little evidence of the back-filling observed at coarser temporal and spatial resolutions. Our observations suggest that avulsion is disproportionately affected by sediment accumulation in the channel, particularly around larger, less mobile grains. Such in-channel deposition can cause channel shifting that interrupts the autogenic avulsion cycle, so that avulsions are aperiodic and their timing is more difficult to predict.
\end{abstract}

*Corresponding author: anya.leenman@alumni.ubc.ca 


\section{Introduction}

Scaled physical experiments have been used to study the periodicity of flow distribution on alluvial fans, with particular emphasis on understanding avulsion, the (relatively) rapid relocation of a channel. Avulsion is a formative process on alluvial fans; successive avulsions build up a fan's characteristic radial morphology. However, avulsion also poses a formidable hazard to people and infrastructure in the avulsion pathway; the inundation of new areas, and associated erosion and deposition, can cause loss of lives and millions of dollars of damage (Chakraborty et al., 2010; Davies and McSaveney, 2008; Korup, 2004; Sinha, 2009). Previous experiments have shown that, even without an "external" stimulus such as a change in flow or sediment supply, channels on fans tend to form, fill with sediment, and avulse, in what can be described as the "autogenic avulsion cycle" (e.g. Clarke et al., 2010; Van Dijk et al., 2012; Reitz et al., 2010; Schumm et al., 1987; Whipple et al., 1998). However, these observations were mostly based on photographic or video evidence, with the supporting topographic information having low spatial or temporal resolution; as a result, hypotheses concerning the causes of avulsion have not had finely-resolved topographic data to support them. Consequently, the physical processes driving avulsion on fans remain an open question, and one that is key to understanding alluvial fan dynamics and the related natural hazards.

Experimental models of fans have suggested that avulsion occurrence and frequency are influenced by fan-channel gradient. Schumm et al. (1987) observed that flow on fans followed a pattern of 1) channelized flow, 2) channel back-filling with sediment, 3) eventual flow-spreading at the fan-head, and 4) fan-head aggradation. They proposed that this fan-head aggradation would increase fan gradient up to a critical value, after which flow avulsed into a single channel, recommencing the cycle. The authors argued that intrinsic gradient thresholds were key to this process. Similar behavior was observed in later experiments by Whipple et al. (1998). Avulsion on fans was further investigated by Bryant et al. (1995), who found that as sediment feed rate increased, the volume of sediment required to cause avulsion decreased. They suggested that fans with higher sediment supply (which had steeper gradients in their experiments) had shallower channels, requiring a smaller volume of sediment to fill the channel and trigger avulsion. However, they lacked sufficiently detailed topographic data to test this. Most recently, Reitz and Jerolmack (2012) proposed that fans adjust to two slope thresholds: a distrainment slope, corresponding to depositional lobes at the fan-toe, and an entrainment slope, corresponding to channelized flow. They hypothesized that the time to avulsion could be estimated from the volume required to fill the "wedge" between these two slopes.

50 These hypotheses were largely informed by visual observations from video or photographs. The supporting topographic measurements in fan experiments have generally been coarsely resolved, in either space or time. For instance, earlier studies of fan and fan-channel evolution monitored topography at a coarse spatial resolution that did not allow channel slope and fan slope to be differentiated. Schumm et al. (1987) used a grid of measuring stakes across the 
55 fan to monitor topographic evolution, while Whipple et al. (1998) used three lines of measuring stakes to monitor topography along three down-fan profiles. More recently, Clarke et al. (2010) used a side-facing camera to view the fan-head through perspex walls, thus monitoring changes in fan-head elevation. While these methods capture overall fan slope, they do not suffice to resolve the slope or dimensions of individual channels. In the past decade, the spatial resolution of topographic measurement in fan experiments has increased, but temporal resolution generally remains low. For example, experimentalists have used either photogrammetry (Van Dijk et al., 2012) or laser-scans (Carlson et al., 2018; Miller et al., 2019; Reitz and Jerolmack, 2012) to collect high-resolution topographic data, that covers their entire experimental landscape with a resolution on the order of a few millimeters. However, these survey methods require that flow be stopped during data collection, meaning that the intervals between full topographic scans ranged from 15 minutes to a few times per experiment. This low temporal resolution impeded the fine-scale monitoring of topographic evolution. With the exception of some experiments by Van Dijk et al. (2012), avulsion occurred at a higher frequency than the topographic scans, so that the influence of topographic change on avulsion 70 and flow pattern evolution was difficult to establish.

In addition to issues with topographic data resolution, few alluvial fan studies have considered the influence of sediment grading on autogenic dynamics, and most have used rather narrowly graded mixtures. For instance, Schumm et al. (1987) and Hamilton et al. (2013) used sand (in the range $0.062-2 \mathrm{~mm}$ and $0.075-2 \mathrm{~mm}$, respectively). Reitz et al. (2010) and Reitz and 75 Jerolmack (2012) used a bimodal mix of $2 \mathrm{~mm}$ granite chips and $0.3 \mathrm{~mm}$ sand, but focused their analysis on the coarse portion alone. Carlson et al. (2018) used a bimodal mix of 1-2 mm and $0.17 \mathrm{~mm}$ sand. Narrowly graded mixtures such as these are poor representations of the mixtures on natural fans; for instance, the $D_{\max } / D_{50}$ ratio in those experiments was $\leq 9$, compared to ratios of 11 - 34 in our samples from gravel fans in Alberta, Canada. Preliminary tests by Hamilton et al. (2013) showed that using a more widely graded mixture produced channels that appeared more "realistic". Similarly, experiments by Booker and Eaton (2020), conducted in a narrow flume designed to represent the aggrading conditions on fans, demonstrated that a narrowly graded mixture failed to reproduce the morphodynamics of a widely graded mixture with the same $D_{50}$. In addition, recent studies have highlighted how the largest grains in a distribution, while often only a small fraction of that distribution, have a disproportionately large influence on channel morphodynamics (MacKenzie and Eaton, 2017; MacKenzie et al., 2018; Williams et al., 2019). Therefore, it is clear that alluvial fan experiments should be conducted with a widely graded mixture based on field data, to more closely represent the complexity of grain interactions that govern the behavior of channels on widely graded natural fans.

9o In light of these issues with previous alluvial fan experiments, we have developed an experimental set-up that allows data-collection at unprecedented temporal and spatial resolution. We use an adaptation of Structure-from-Motion photogrammetry that allows us to collect topographic data without stopping flow. Consequently, we are able to collect co-registered digital eleva- 
tion models (DEMs) and orthophotos, both with $1 \mathrm{~mm}$ resolution, at every minute during the experiment. By collecting topographic and photographic data at identical spatial and temporal resolution, we are able to explore how flow patterns and topography are interrelated. Moreover, this high-frequency, high-resolution dataset gives us a deeper understanding of avulsion on alluvial fans, by allowing us to monitor topography before, during and after avulsion.

We present results from an alluvial fan experiment with constant flow and sediment feed, using a widely graded sediment mixture. Using high-resolution, high-frequency data collected during the experiment, we aim to:

1. characterize temporal changes in flow distribution on the fan, and thus characterize the periodicity (or lack thereof) of the autogenic avulsion cycle;

2. characterize the changes in topography associated with avulsion and periods of channelized flow, to compare our experiment to existing understandings of the avulsion cycle;

3. understand the linkages between topographic change and flow pattern adjustment.

Ultimately, we compare our results to those of previous experiments with more narrowly graded mixtures and more coarsely-resolved topographic data. We consider the influence of our widely graded sediment mixture, and of local peaks in sediment flux resulting from bank erosion and incision. In particular, we emphasize how flow patterns on fans (and both rapid and subtle change thereof) are influenced by in-channel sediment deposition.

\section{Methods}

\subsection{Experimental details}

We conducted the experiment using a physical model of a generic gravel-cobble alluvial fan. We built the fan in a $2.44 \times 2.44 \mathrm{~m}$ stream table with $0.3 \mathrm{~m}$ high walls (Figure 1), with a 0.2 $\times 0.5 \times 0.3 \mathrm{~m}$ feeder channel extending from a corner. Water was input from a constant head tank with an adjustable outflow. Sediment was gravity-fed through a rotating pipe, with the rate controlled by the angle of the pipe. Sediment and water were mixed in a funnel and then disgorged into the head of the feeder channel. We allowed sediment to aggrade and degrade freely in the feeder channel, as in a natural system.

We used constant rates of flow $\left(150 \mathrm{~mL} \mathrm{~s}^{-1}\right)$ and sediment feed $\left(5 \mathrm{~g} \mathrm{~s}^{-1}\right)$. The flow rate scales approximately to the 20 year flood on Three Sisters Creek fan, Canmore, Canada. However, the experiment is not a Froude-scaled model of this site, but a generic similarity-of-process model of gravel-cobble alluvial fans (see below). We adjusted the sediment feed so that the sediment concentration was typical of fully fluvial flow, at $\sim 1.8 \%$ by volume. We ran the exper- 


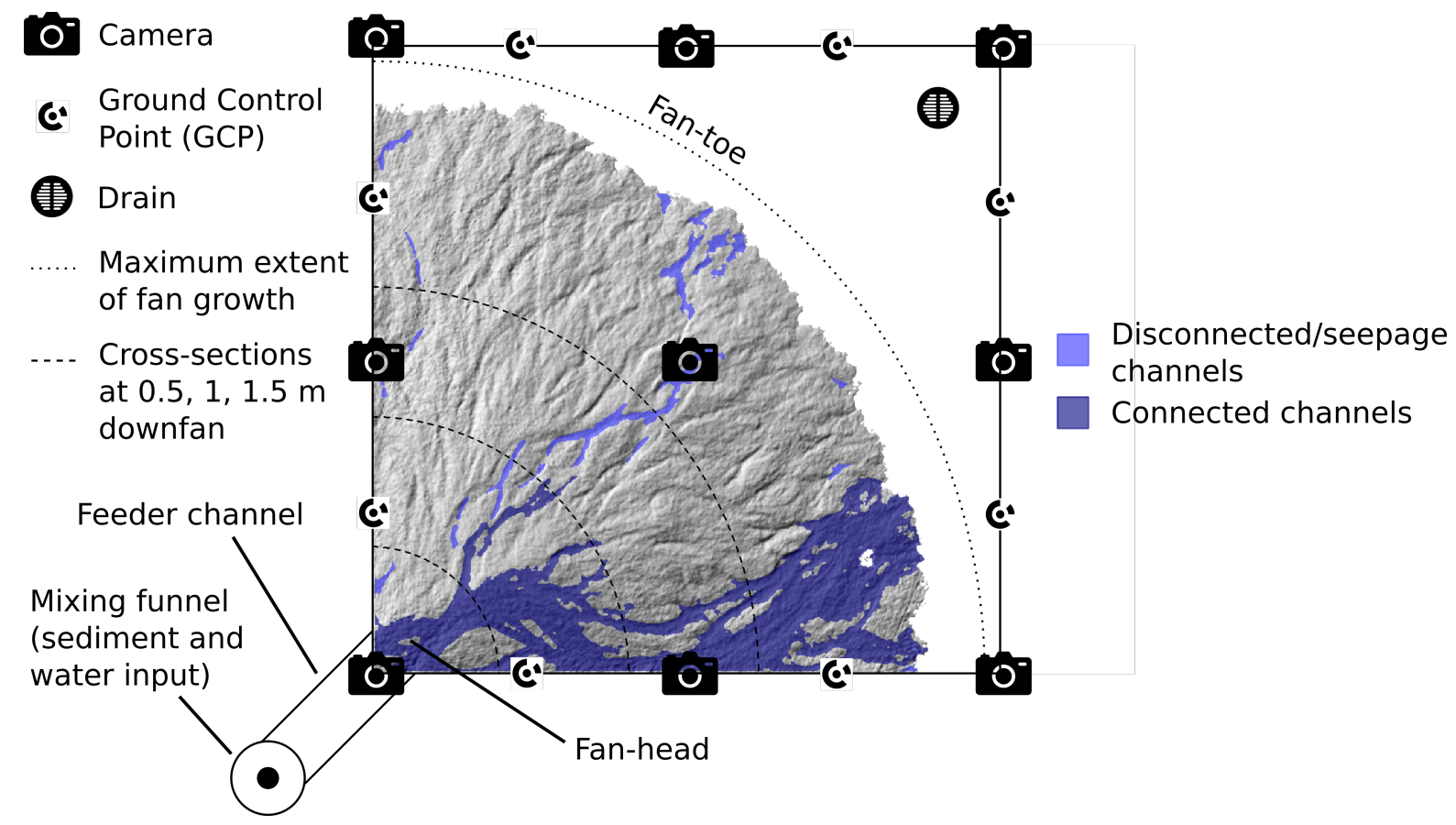

Figure 1: Schematic diagram of the experimental set-up. Water and sediment are mixed in a funnel and disgorged into the feeder channel, where sediment is allowed to freely aggrade and degrade. Example topography and flow map are at 18 hours, 40 minutes.

iment for $\sim 20$ hours, which was approximately the time required for the fan to prograde to the table edges. This period was long enough to observe the processes of fan evolution, including numerous avulsions and phases of surface reworking. We ran three repeats of the experiment (all 20 hours long); most data presented in this paper is from the first repeat, but supporting data from the second and third repeats are provided in the Supplementary Material.

The stream table was set to a slope of $0.0002 \mathrm{~m} \mathrm{~m}^{-1}(0.02 \%)$ with the feeder channel at the highest point. This was the minimum angle required to generate flow toward the drain at the opposite corner. To increase boundary roughness, we glued $2 \mathrm{~mm}$ sand grains and Lego sheets to the base and walls of the table. Water in the experiment was dyed blue, allowing photos to be used for automated channel mapping.

We used a widely graded sediment mixture, which was approximated from a surface gravel sample from Three-Sisters Creek fan using a length scale of 1:128. The experimental mixture ranged from $0.25 \mathrm{~mm}$ to $8 \mathrm{~mm}$, with $95 \%$ of the mixture finer than $2.3 \mathrm{~mm}$ (Figure 2). Subsurface flow through pores in the sandy mixture meant that seepage channels formed as the fan grew. This behavior is not uncommon; field studies have reported considerable streamflow loss through infiltration on fans, which is thought to explain down-fan channel narrowing and the formation of springs on the lower portion of some fans (Davidson et al., 2013; Kesel and Lowe, 1987; Woods et al., 2006).

Toward the end of the experiment, the fan developed a slight convexity (Supplementary Material, Figure S2). This convexity is unlikely to occur on natural fans, which generally have straight 


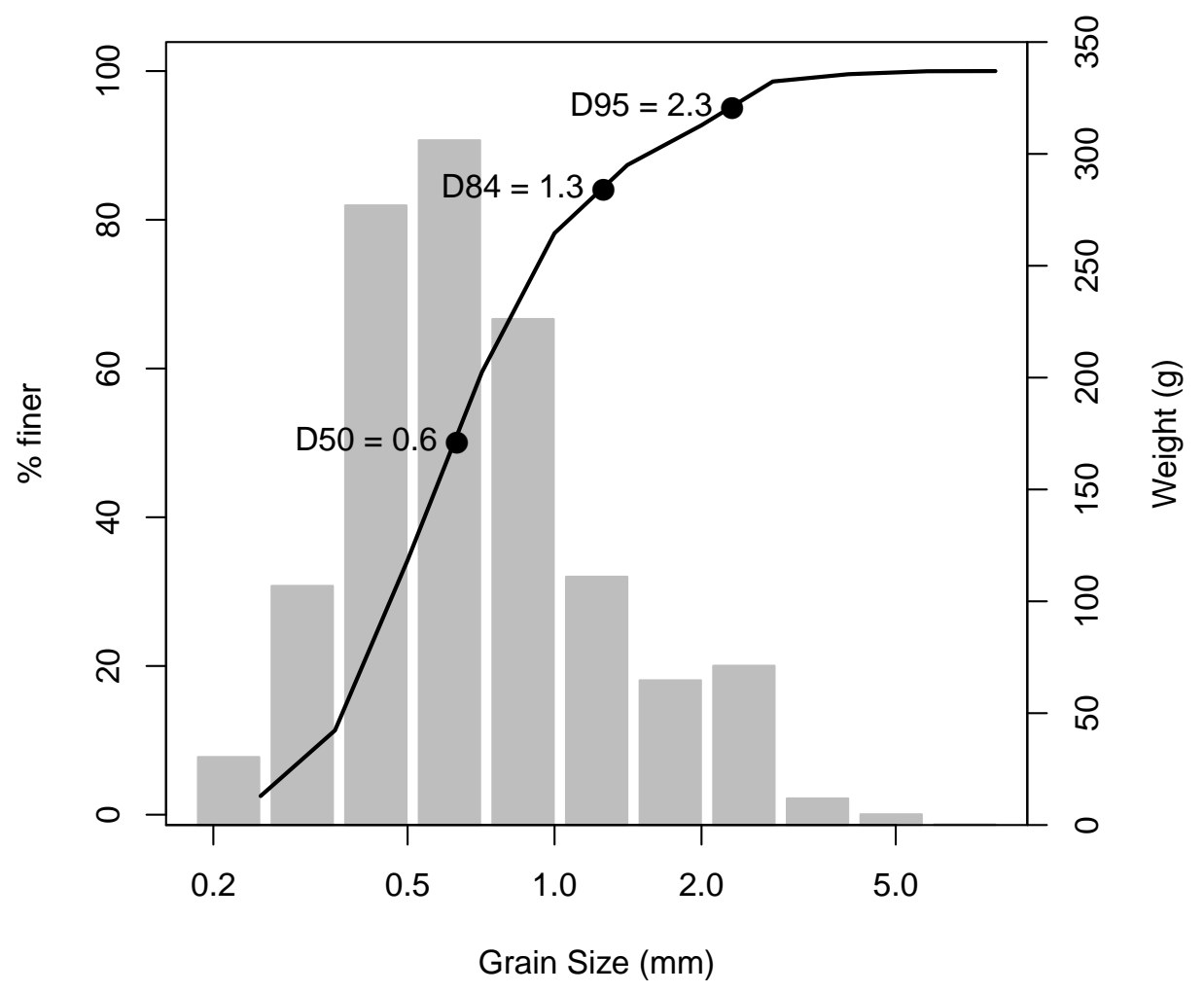

Figure 2: Grain size distribution (GSD) of the sand and fine-gravel mixture in the experiments. Line and points correspond to the primary $y$-axis, and the histogram to the secondary $y$-axis.

or concave-up long profiles (e.g. Beaumont, 1972; Blair and McPherson, 1994; Blissenbach, 1952; Bull, 1977; Denny, 1965; Eckis, 1928). We conducted a range of tests across all experimental repeats to establish if the convexity influenced our various measures of flow patterns, topography, and change thereof. None of these relations had $r^{2}>0.18$ (Table S5, Supplementary Material), suggesting that the convexity did not strongly affect the other variables we measured.

\subsubsection{Similarity-of-process modeling}

The fan slope (typically $0.05-0.07$ ) and the channels upon it were self-formed, so it was impossible to control the Froude number, mean channel width, or mean hydraulic depth. As a result, the model is most appropriately interpreted as a "similarity-of-process" model (c.f. Hooke, 1968a), and not a Froude-scaled model. Because of the large length scale required to simulate the 3D evolution of fans within a reasonable time-frame and spatial extent, similarity-of-process models ("analogue models") have become the established norm in laboratory studies of fans and fan-deltas (e.g. Bryant et al., 1995; Clarke et al., 2010; Davies and Korup, 2007; Van Dijk et al., 2009; de Haas et al., 2016; de Haas, Kruijt and Densmore, 2018; Hamilton et al., 2013; Hooke, 1967, 1968b; Hooke and Rohrer, 1979; Miller et al., 2019; Piliouras et al., 2017; Reitz 
and Jerolmack, 2012; Schumm et al., 1987). A similarity-of-process model is one that reproduces key aspects of the morphology of the generic "prototype"; importantly, the processes that shape this morphology in the model can reasonably be assumed to do so in the field. Because it was impossible to control flow widths and depths on the fan, we have estimated the typical hydraulic parameters at the fan head, where the flow width is constrained. There, the Froude number was estimated to be $\sim 1.9$ on average, consistent with observations of supercritical flow on fans (Beaumont and Oberlander, 1971; Rahn, 1967), although we estimate that it fell below 1 as flow spread out across the fan. The typical Reynolds number at the apex was estimated to be $\sim 1200$, putting the flow in the transitional zone between laminar and turbulent flow, which violates the typical requirement for "Froude-scaled" models that the flow remain turbulent. Furthermore, the particle Reynolds number at the apex was estimated to be $\sim 66$ (when calculated using the $D_{84}$ as a representative grain size), which also violates the minimum value of 70 recommended by Schlichting and Gersten (2016) and by Yalin (1971), but conforms to the threshold of 15 proposed by Parker (1979) and by Ashworth et al. (1994). Flows that were not fully turbulent have been reported in a diverse range of alluvial fan experiments (e.g. Davies et al., 2003; Davies and Korup, 2007; Delorme et al., 2017, 2018; Van Dijk et al., 2012; Guerit et al., 2014; Hamilton et al., 2013; Reitz et al., 2010; Reitz and Jerolmack, 2012; Whipple et al., 1998). Despite this lack of dynamic similarity (comparable hydraulic conditions in model and prototype), these models have successfully reproduced the processes of fan evolution, channel dynamics, surface reworking and avulsion that are of interest to us.

In summary, the large length ratio necessary to conduct experiments on fan evolution make it difficult to establish dynamic similarity, which must be kept in mind when interpreting our results. In particular, we feel that extrapolations of rates and volumes measured in our model to a prototype fan are probably inappropriate without additional supporting information from the field. However, we believe that the morphologic processes are reasonably well represented.

\subsubsection{Data Collection}

We monitored topography and flow patterns using an adaptation of "Structure-from-Motion" (SfM) photogrammetry (Fonstad et al., 2013; Westoby et al., 2012). Nine digital single-lens reflex cameras were mounted above the experiment (Figure 1). The cameras captured synchronous images of the fan at one-minute intervals. Using eight ground control points (GCPs) on the table walls, we georeferenced the images to a local coordinate system. To better resolve fan topography, the GCPs were placed in alternating high and low positions on the walls, separated by $\sim 15 \mathrm{~cm}$; the maximum height of the fan apex in any experimental repeat was $\sim 17$ $\mathrm{cm}$. Synchronous image sets were processed in Agisoft Photoscan to produce point clouds ( 280,000 points per $\mathrm{m}^{2}$ ) and orthophotos ( $1 \mathrm{~mm}$ resolution). Further details on the SfM methods are provided in the Supplementary Material. 


\subsection{Analysis}

We briefly summarize our analysis here, with further detail in the Supplementary Material. All analysis was conducted in $\mathrm{R}$ (R Core Team, 2019). We limited the spatial extent of the analysis to areas where the fan had built to $>6 \mathrm{~mm}$ above the initial (empty) surface.

Using the topographic point clouds as source data, we generated DEMs with $1 \mathrm{~mm}$ resolution. We compared successive DEMs in order to quantify topographic change (deposition and erosion) in each minute of the experiment.

Using the orthophotos as source data, we mapped flow. Because the water in the experiment was dyed blue, flow had a strong signal in each color band. We thus developed a color index to emphasize flow. We calculated the index for every cell, and applied a threshold to isolate flow areas. To remove noise, we sieved out clumps below a threshold size, and applied a smoothing filter. We used these flow maps to identify avulsion events and periods of channelized flow.

\subsubsection{Identifying avulsion}

We used two methods to characterize the periodicity of the autogenic cycle: 1) examining the periodicity of avulsion (i.e. large-scale channel reorganization), and 2) examining the periodicity of channelized flow (versus sheetflow, or flow widely spread among distributaries).

To identify avulsion, we developed an automated method in which we compared pairs of flow maps (performing change detection between them). As the duration between flow maps increased, so did the magnitude of differences between them (e.g. Supplementary Material, Figure S6). To measure the duration that was most appropriate for identifying avulsion, we conducted a preliminary visual inspection of the orthophotos (Table S6). Based on this, we selected a three-minute lag between flow maps. We thus compared minute 1 to minute 4 , minute 2 to minute 5 , and so on.

For each flow map pair, we measured the area newly occupied by flow, and the area abandoned by flow. Any pair in which both new and abandoned flow exceeded $10.5 \%$ of fan area was classified as avulsion. These were major avulsions, with the avulsion node often at the fan-head (Figure 3(a)). We trialed a range of thresholds, and chose $10.5 \%$ as it isolated the majority of avulsions observed manually, while minimizing the number of "false positives" - that is, avulsions identified using the automated method that were not identified manually. The threshold corresponded approximately to the $89^{\text {th }}$ percentile of new and abandoned flow areas. If the threshold was exceeded for two successive flow map pairs (e.g. t1-t4 and t2-t5), this was counted as a single avulsion.

In addition to avulsion, we defined two other classes of channel reorganization event: divergence and convergence. Flow "divergence" events are similar to avulsion: flow spreads out in multiple distributaries, so the newly occupied area is large, but the original channel is not 
a) Avulsion, $\mathrm{t}=1359$

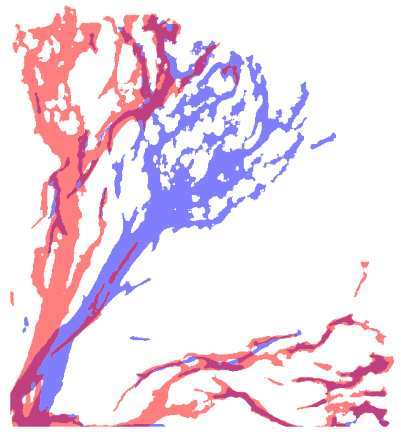

c) Convergence, $t=1704$

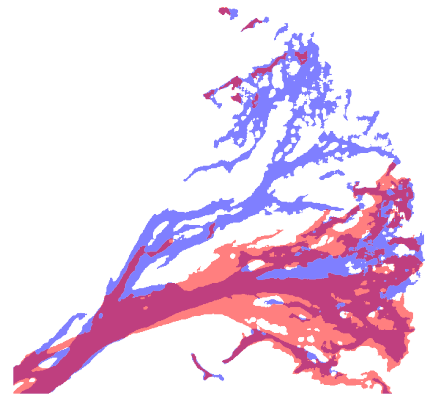

b) Divergence, $\mathrm{t}=1842$

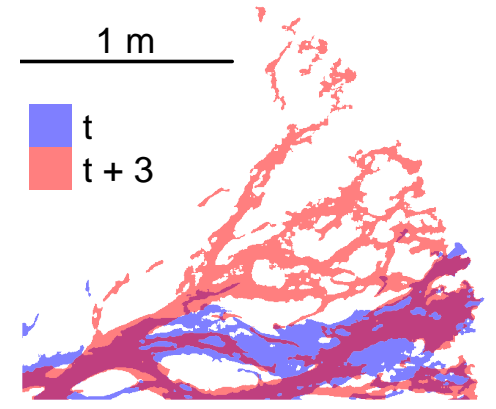

d) Low-mobility, $t=1255$

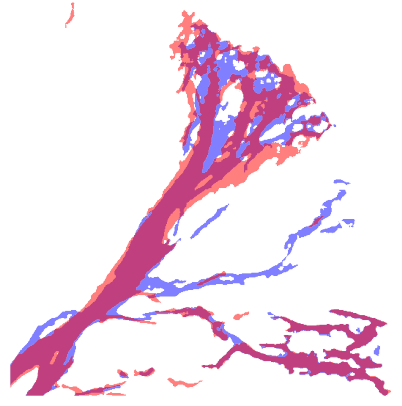

Figure 3: Examples of the three classes of channel reorganization event (avulsion, divergence and convergence) and low-mobility periods, identified using the automated flow map comparison. The avulsions (a) we identify are major avulsions with large-scale relocation of flow. Divergence events (b) are when flow spreads out across a large area (this may include small avulsions) but the original channel is not abandoned. Convergence events (c) are when flow collects into a subset of the existing flow paths. Low-mobility periods (d) are when both new and abandoned flow are $<5.8 \%$ of the fan.

abandoned (a key difference from avulsion). We defined divergence as events with new flow area $>10.5 \%$ of the fan (as for avulsion) but abandoned flow area $<8 \%$ of the fan. Divergence may include minor avulsion or crevasse-splay, as in Figure 3(b). In terms of surface reworking (and on natural fans, geohazards), divergence events have a large impact, similar to avulsion, but we classify them separately because the original channel is not abandoned.

Flow "convergence" events are those in which the new flow area is small, but the abandoned area is large, as flow collects into a subset of the existing channels; these events may initiate a period of channelized flow. We defined convergence as events with new flow area $<8 \%$ of the fan, and abandoned flow area $>10.5 \%$ (Figure 3(c)). Finally, we defined a fourth class of "low mobility" periods, when both new and abandoned flow area were $<5.8 \%$ of the fan (Figure 3 (d); the threshold corresponded to the $11^{\text {th }}$ percentile of new flow area, mirroring the $89^{\text {th }}$ percentile defining avulsion). The three classes of channel reorganization mark a major change in channel pattern, and we treat them as instantaneous events. In contrast, the "low-mobility" state is defined by a lack of change, and can persist for multiple successive time-steps. 


\subsubsection{Identifying periods of channelized flow}

As an additional metric for the periodicity of the autogenic cycle, we examined the recurrence of channelized flow. To identify periods of channelized flow, we again used the flow maps, and we first removed disconnected/seepage channels (Figure 1) to avoid overestimating the number of active channels. We then extracted the flow map at an arcuate cross-section, $1 \mathrm{~m}$ down-fan (marked in Figure 1). We counted the number of channels along the transect (automatically, by counting intersections between the flow map and the transect), and estimated the width of the sector in which flow was active (measuring along the arcuate transect).

We used this last variable, the width of the active sector, to identify periods of channelized flow. When flow was confined to a single channel at the $1 \mathrm{~m}$ transect, the active sector width did not exceed $0.325 \mathrm{~m}$. Consequently, we defined channelized flow as any period when the active sector at $1 \mathrm{~m}$ down-fan was $<0.325 \mathrm{~m}$ wide. Further details on this method are given in the Supplementary Material (section $\mathrm{S} 1.3$.

We placed the transect at $1 \mathrm{~m}$ down-fan as it was approximately twice the bar wavelength visible in the orthophotos, and was therefore located multiple path lengths down-fan from the inlet (e.g. Pyrce and Ashmore, 2003). $1 \mathrm{~m}$ is far enough down-fan that changes in flow pattern there represent changes on the fan as a whole.

\subsubsection{Topographic change and channel geometry analysis}

We conducted topographic change detection using minute-to-minute "DEMs of Difference" (DoDs). The DoDs quantified the location and volume of deposition and erosion, in each minute of the experiment. For each patch of deposition and erosion, we measured the local gradient, and estimated flow width and depth, to ascertain how deposition and erosion were affecting channel dimensions. We briefly summarize these methods below; a detailed description is in the Supplementary Material (section S1.4).

We smoothed the DEMs to remove small pits and sinks (with a $7 \times 7 \mathrm{~mm}$ moving average filter). We then subtracted each DEM (t1) from the DEM at the following time-step (t2). The resulting DoD ( $\mathrm{t} 2$ - $\mathrm{t} 1$ ) had positive values where the fan had aggraded, and negative values where it degraded. There was some uncertainty in the DEMs' vertical accuracy, resulting in part from light diffraction through water (for a detailed topographic error analysis, see Supplementary Material, section S1.5). To account for vertical uncertainty, we thresholded each DoD at $2 \mathrm{~mm}$, discounting elevation change in the range $-2 \mathrm{~mm}<x<2 \mathrm{~mm}$. This process created distinct patches of aggradation (deposition) and degradation (erosion; we use these terms interchangeably).

${ }_{280}$ For each patch of deposition or erosion in the DoD, we measured the down-fan gradient, and estimated flow width and depth. We measured gradient along a radial profile from the fan- 
head through the patch centroid. We estimated flow width from the flow maps, for a sample of patches at $0.5 \mathrm{~m}$ intervals down-fan. We estimated flow depth from water color intensity in the orthophotos. We performed each measurement or estimate twice, using data from the timestep before (t1) and after (t2) the DoD. Further detail on the steps involved in these analyses is provided in the Supplementary Material (section S1.4).

\subsubsection{Data subset}
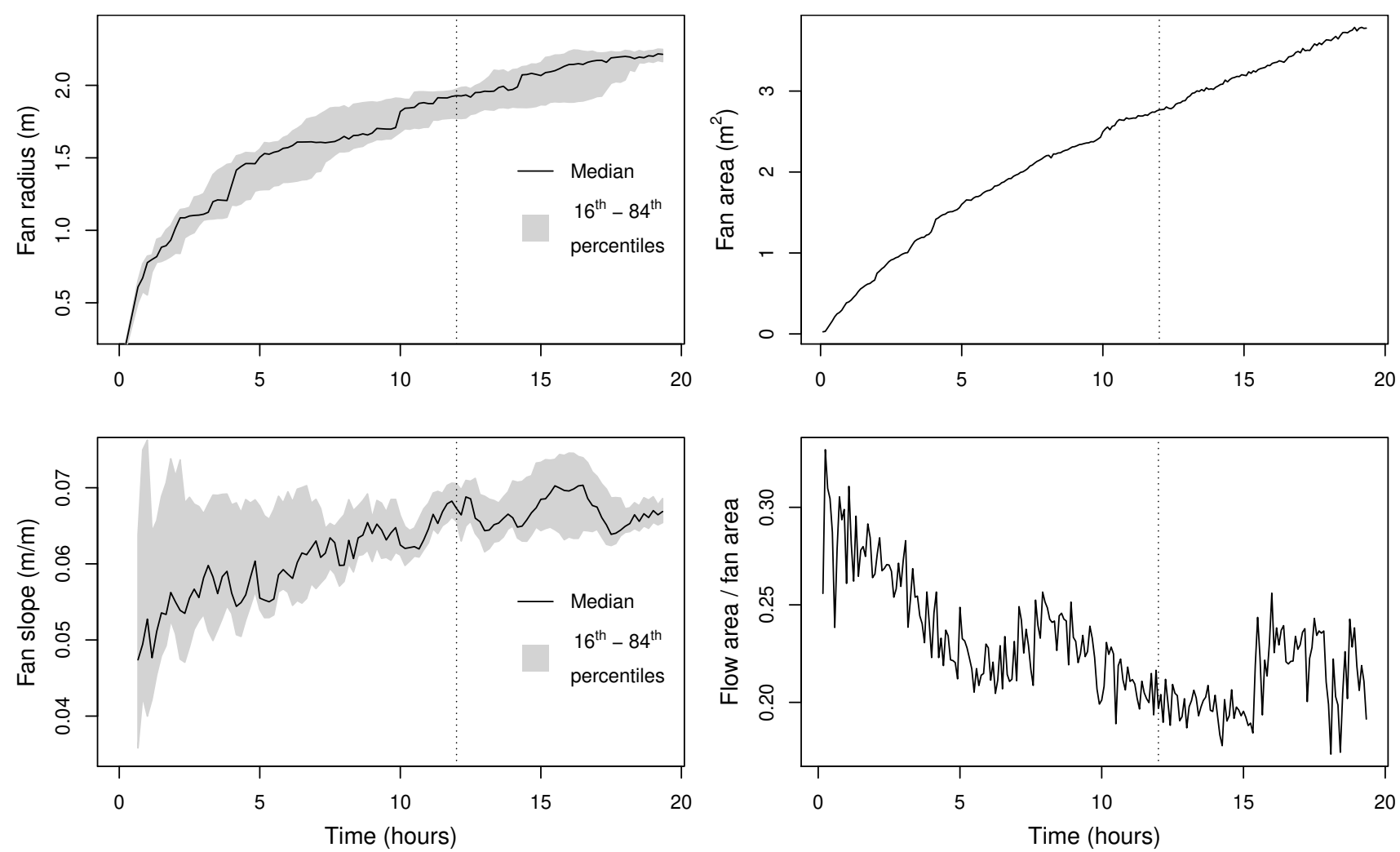

Figure 4: Change in fan radius, slope, area and wet fraction (flow area / fan area) during the experiment. The dotted vertical line marks $t=12$ hours, after which slope and wet fraction were more independent of fan size. Radius and slope distributions are from 88 equally-spaced down-fan profiles.

The data we present in this paper are a subset of the total experiment length, from $t=12$ hours to $t=19: 23$ hours (the end of the first experimental repeat). This was due to the scale dependence of fan dynamics earlier in the experiment, when the fan slope (in particular) and wet fraction were related to fan area and radius (Figure 4). After $\sim 12$ hours, the rates of change in fan slope and wet fraction (and, we infer, fan morphodynamics in general) were less dependent on fan size. Other fan studies have similarly discarded the initial "spin up" period of experiments (e.g. Reitz et al., 2010; Reitz and Jerolmack, 2012), and Clarke et al. (2010) described in detail how flow patterns differ between the early and later stages of fan growth. 


\section{Results}

\subsection{General Observations}

The experiment time-lapse video (https://youtu.be/Pc_2iyCDeaI or Figure 5) shows that flow patterns on the fan were highly dynamic; channel pattern rearrangement was rapid and continuous. For instance, the video shows that from 13:00 - 14:00, flow traversed almost all of the fan surface. Channels were formed and destroyed in just a few minutes (e.g. repeatedly from 16:00-16:15), and lateral mobility was high (e.g. 12:30 - 13:00). Flow was almost always multi-threaded, and the number of channel threads and total flow width increased downstream (Supplementary Material, Figure S7 and S8). We also observed down-fan alternation between flow-spreading and channelization zones, as noted by Schumm et al. (1987) in experiments and by Field (2001) on fans in Arizona.

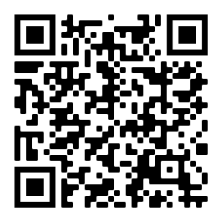

Figure 5: Link to the experimental time-lapse video.

\subsection{Characterizing flow distribution}

Our first aim was to characterize temporal changes in flow distribution on the fan, and thus characterize the periodicity of the autogenic avulsion cycle. We did so by a) manually identifying channel reorganization events (including avulsion); b) automatically detecting channel reorganization events, and c) automatically detecting periods of channelized flow.

\subsubsection{Manual event classification}

We conducted a preliminary manual inspection of channel reorganization in the orthophotos from our first experimental repeat. We identified large-scale reorganization events, and subjectively classified them as either avulsion (major avulsion, typically from the fan-head), divergence (flow spreads rapidly across the fan, but the old channel is not abandoned) or convergence (multiple distributaries become concentrated into a small number of channels); examples are shown in Figure 3. 
The time between manually identified avulsions was 2-181 minutes (median $=34.5$ minutes).

\subsubsection{Flow area analysis}

To corroborate our manual identification of channel reorganization events, we compared pairs of flow maps that were three-minutes apart (the median duration of the events identified man- 
ually). In our first experimental repeat, this automated method identified eight of the nine avulsions identified manually, with one "false positive". These avulsions are shown in Figure 6, along with divergence and convergence events, and periods when our criteria for "low-mobility" were met. The time between avulsion events was 2-139 minutes (median = 33.5 minutes). For the sequence of all event types, the time between events was $1-83$ minutes (median $=10$ minutes). Data for the second and third experimental repeats are provided in the Supplementary Material (Table S7).

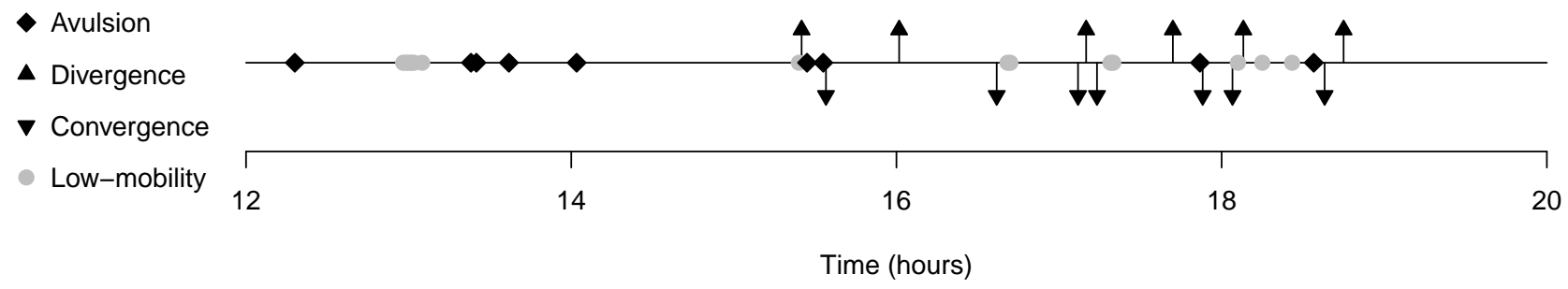

Figure 6: The time series of channel reorganization events (avulsion, divergence and convergence) and low-mobility periods.

In between the channel reorganization events and "low-mobility" periods, there was a moderate degree of lateral channel migration, during which the areal change between pairs of flow maps was too high to meet our criteria for low-mobility, but too low to meet our criteria for channel reorganization. Channel reorganization events made up 60 minutes in total, and the low-mobility periods made up 14 minutes, so this "moderate" mobility persisted for 369 minutes, or $80 \%$ of the period of the experiment that we analyzed.

To quantify the periodic nature of the automatically detected channel reorganization events, we again calculated $A_{n}$ (Table 11, rows 3-4). $A_{n}$ was close to zero, both for avulsion and for the sequence of all events, again implying a random (aperiodic) occurrence in time $A_{n}$ values for all experimental repeats are given in the Supplementary Material (Table S8).

We also applied the avulsion size metric of Densmore et al. (2019) to the automatically detected avulsions. Again, these were apical avulsions, with normalized upstream distance of $0.69-0.90$ (mean of 0.81 ), and normalized opening angles of $0.17-0.52$ (mean of 0.31 ). Avulsion size therefore ranged from $0.12-0.45$ with a mean of 0.25 .

\subsubsection{Channelized flow (cross-section analysis)}

We assessed the periodicity of channelized flow at a mid-fan cross-section, as an additional means to characterize the periodicity of the autogenic cycle. Periods of channelized flow are marked pale red in the background of Figure 7 , which shows how flow patterns evolved during the experiment. 
Active channels $\square$ Disconnected channels Period of channelized flow

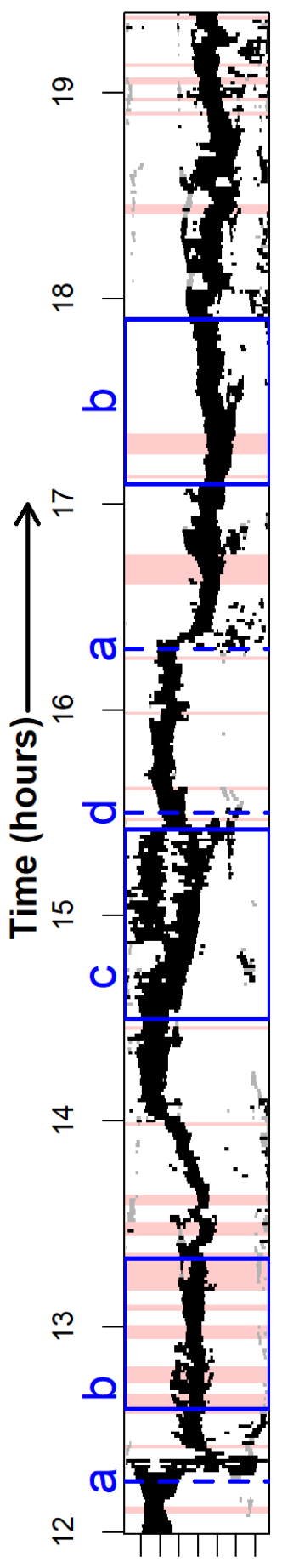

0.10 .5

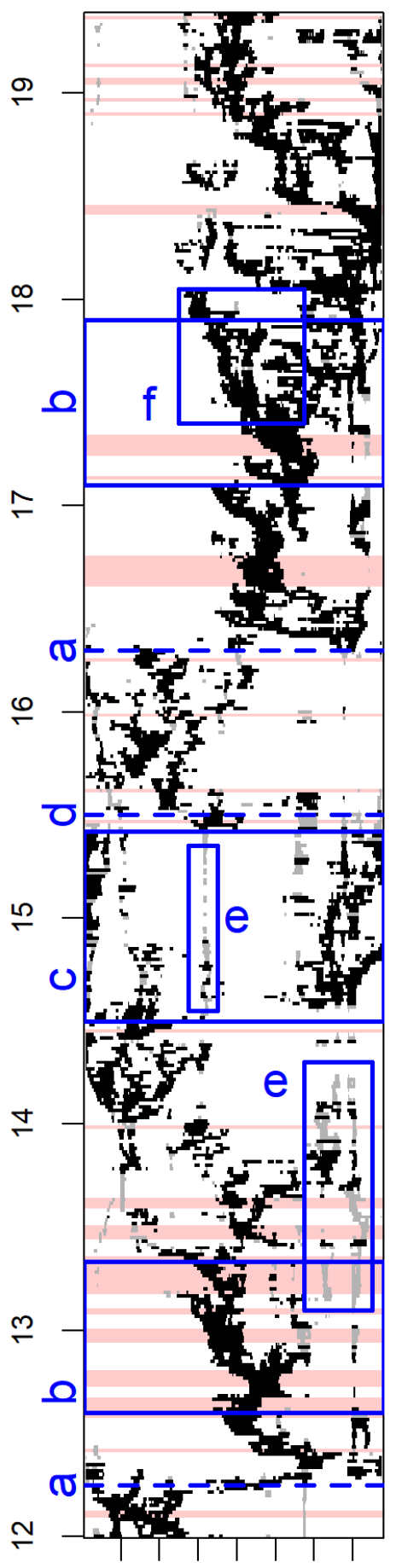

$\begin{array}{llll}0.2 & 0.6 & 1.0 & 1.4\end{array}$

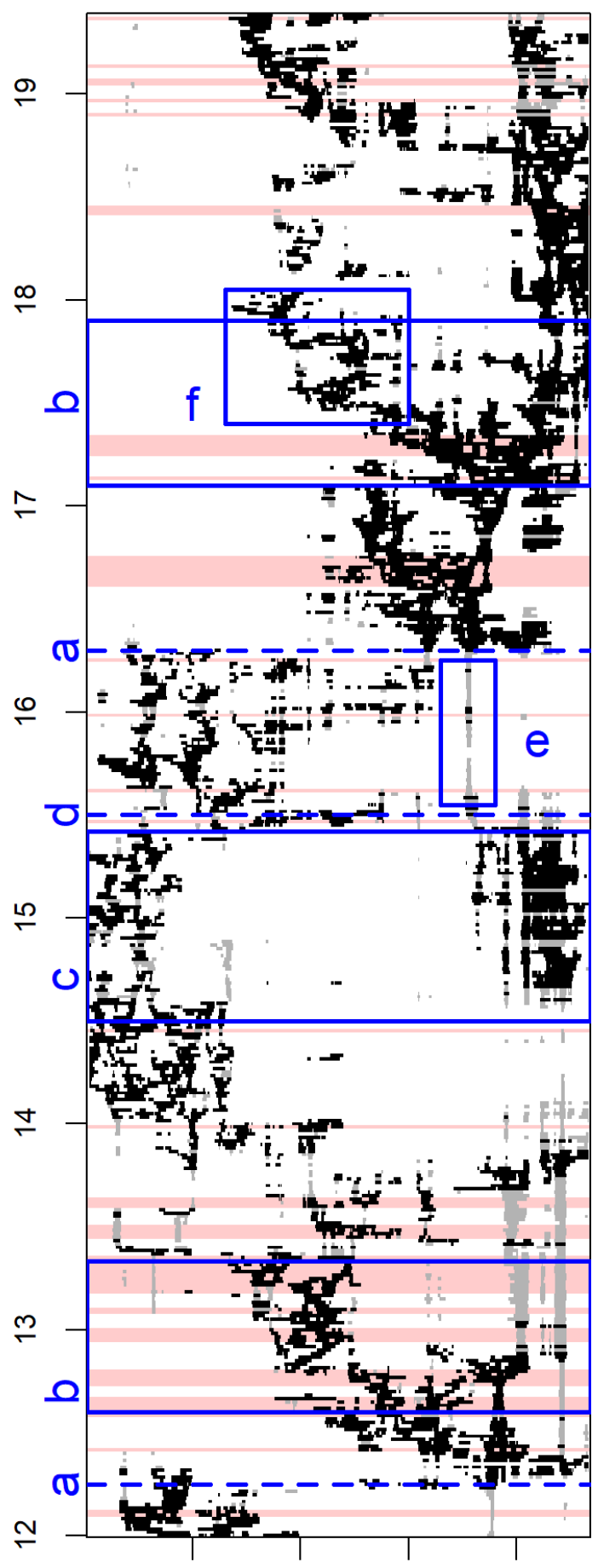

$\begin{array}{llll}0.5 & 1.0 & 1.5 & 2.0\end{array}$

Distance along fan, facing downstream (m)

Figure 7: The temporal evolution of channel pattern, at three arc-cross-sections. Panels show the channel at $0.5 \mathrm{~m}$ (left), $1 \mathrm{~m}$ (center) and $1.5 \mathrm{~m}$ (right) down-fan; Figure 1 shows the transect locations. Channelized flow periods are highlighted pale red. Letters a-f correspond to descriptions in text. 
Figure 7demonstrates that channelized flow was aperiodic. It also reveals a suite of characteristic channel patterns and behaviors, annotated in the figure as follows:

a) Rapid lateral sweep from one sector to another.

b) Active sector widening gradually (after avulsion or convergence events, or a period of channelized flow).

c) Bifurcated state: flow spread across a wide sector. The largest channel thread often oscillated between branches, with active flow abandoning one branch for short periods.

d) Convergence, with most flow converging into a subset of the existing channels.

e) Maintenance of abandoned-channels as seepage channels. These periodically attracted active flow.

f) Minor channel rearrangement, or variation in flow partitioning, at the mid-fan region having a larger influence on flow patterns toward the fan-toe.

Many of these behaviors were also accompanied by lateral migration. For instance, the gradual widening of the active sector at both instances of Figure 7(b) was achieved through lateral migration of one channel branch away from another. This gradual change in flow location occurred over relatively more time than the rapid changes at (a) and (c).

Other studies have used the frequency of channelized flow to characterize the autogenic cycle on fans (e.g. Carlson et al., 2018). Consequently, we again applied the Kim and Jo (2016) burstiness parameter $A_{n}$ to the time series of channelized flow periods (specifically, the onset of each period) shown in Figure 7. We found $A_{n}=-0.048$ for the onset of channelized flow, suggesting that the signal was random (and thus aperiodic). Normalizing the inter-event intervals by fan radius reduced $A_{n}$ to -0.065 .

\subsection{Flow distribution and topography}

Our second aim was to characterize the changes in topography associated with avulsion and periods of channelized flow. Using DEMs of Difference (DoDs) generated from our topographic data at one-minute intervals, we tracked deposition and erosion patterns through space and time, following the onset of channelized flow or avulsion. A sample is shown in Figures 8 and 9 (following channelized flow) and Figure 10 (following avulsion). These examples display behaviors that were characteristic of many channelized flow periods and avulsion events. The Supplementary Material contains the full datasets for all channelized flow periods (Figure S9 s29) and avulsion events (Figure S30- S36).

Some previous fan experimental studies reported back-filling after the onset of channelized flow (Carlson et al., 2018; Reitz and Jerolmack, 2012; Schumm et al., 1987). In contrast, Figures 8 and 9 do not show a clear signal of back-filling. In Figure 8, it is possible to discern a very

small $\left(\sim 20 \mathrm{~cm}^{2}\right)$ patch of deposition that slowly moved up-fan during the five-minute period 


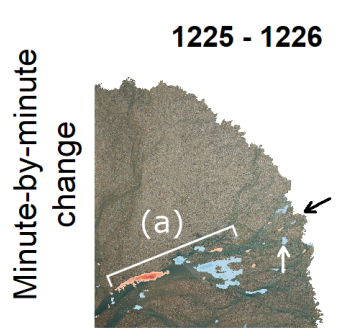

$1225-1226$

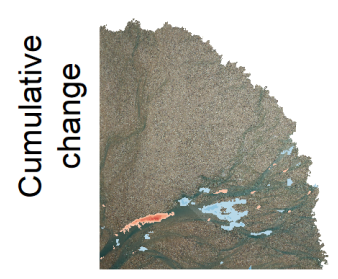

$1226-1227$

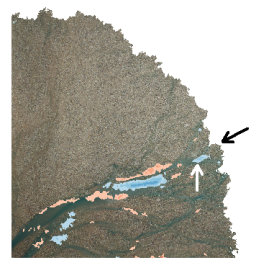

$1225-1227$

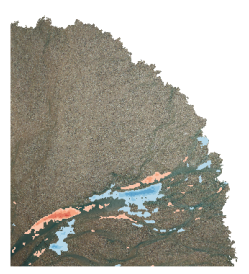

$1227-1228$

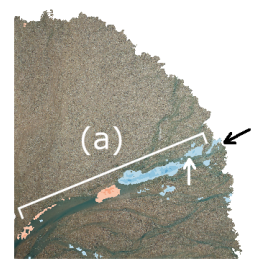

$1225-1228$

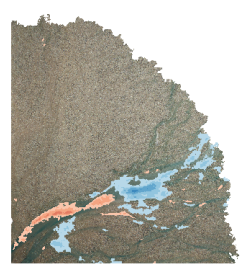

$1228-1229$

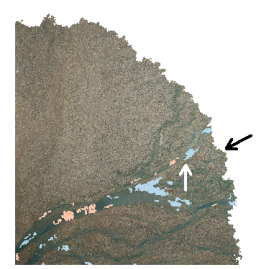

$1225-1229$

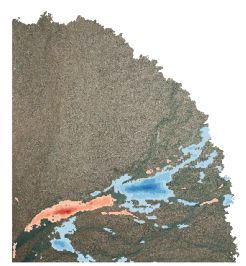

$1229-1230$

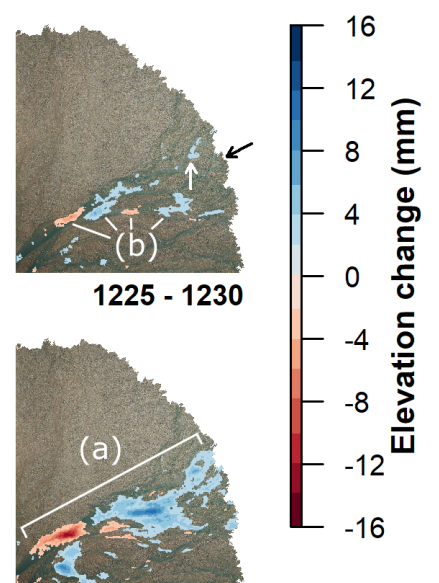

Figure 8: DEMs of difference (DoDs) for the five minutes after the onset of channelized flow at 12:25. Upper panel: minute-to-minute topographic change. Lower panel: cumulative topographic change. (a) = erosion-deposition "couplets"; (b) = down-fan alternation of aggradation and degradation.

(denoted by movement of the white arrow; the black arrow is fixed for comparison). However, this small depositional patch did not appear to influence flow dynamics across the channel belt; by the fourth minute (12:29), a minor avulsion on the lower fan had shifted flow farther "south", disconnecting sediment supply to the depositional patch.

Three characteristic patterns become clear in Figures 8 and 9. These are:

(a) Erosion-deposition "couplets", similar to those observed by Whipple et al. (1998). These couplets occur when channelized flow on the upper fan acts as a conduit for sediment transport, focusing deposition on the lower fan.

(b) Down-fan (spatial) alternation of aggradation and degradation patches (more clear in Figure 9), showing that even during channelized flow, the channel does not always act as a conduit for transport as in (a).

(c) Downstream migration of large depositional patches (Figure 9, from 19:00 onward).

The lower panel of Figures 8 and 9 shows how deposition and erosion aggregate as the time between DEMs lengthens. The erosion-deposition couplets in Figure 8 become clearer. In addition, patches of deposition grow both upstream and downstream simultaneously.

After avulsion (Figure 10, two characteristic behaviors were revealed:

(a) Bifurcation tended to be a locus of deposition. The accumulated deposition could trigger flow convergence into one channel thread.

(b) Minor back-filling persisted for just a few minutes before a minor avulsion redirected flow farther to the "south". 

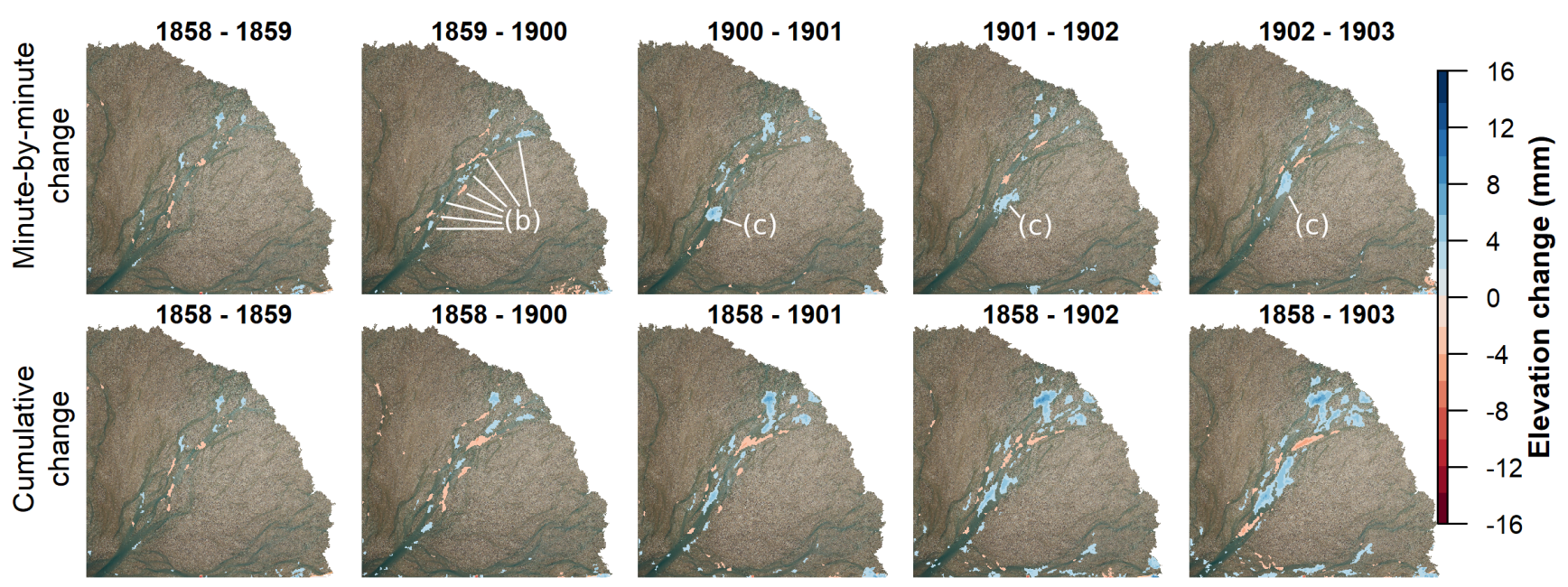

Figure 9: DEMs of difference (DoDs) for the five minutes after the onset of channelized flow at 18:58. Upper panel: minute-to-minute topographic change. Lower panel: cumulative topographic change. (b) = down-fan alternation of aggradation and degradation; (c) = large depositional patch moving down-fan.

In summary, Figures 8 - 10 show that channelized flow had the potential to convey sediment to the lower fan, and that bifurcations tended to be depositional loci. However, these figures provide little evidence that back-filling, or upstream-progressing deposition, was a dominant process. When minor back-filling was observed, it was short-lived, with lateral migration or small avulsions on the lower fan tending to redirect flow after a few minutes.

\subsection{Local topography}

Our third aim was to understand the linkages between local topographic change and flow pattern adjustment. Given that we found little evidence of back-filling, we wanted to test whether local slope was in fact related to deposition (and, we can infer, distrainment), or whether other aspects of channel geometry were important. We therefore estimated channel geometry for the deposition and erosion patches revealed in the DoDs. For each patch, we measured local down-fan slope, and estimated channel width and depth. We did so for the time-steps both prior to (t1) and following (t2) the deposition or erosion measured in the DoD.

If local slope was an important driver of deposition (and hence distrainment), we would expect depositional patches to have lower slopes than erosional patches, at $\mathrm{t} 1$. However, the populations of deposition and erosion patches had similar distributions of slopes at $\mathrm{t} 1$ (Figure 11a); the population mean was $0.061 \mathrm{~m} \mathrm{~m}^{-1}$ for deposition and $0.060 \mathrm{~m} \mathrm{~m}^{-1}$ for erosion (standard deviation $=0.030$ and $0.037 \mathrm{~m} \mathrm{~m}^{-1}$, respectively). At $\mathrm{t} 2$ (Figure $11 \mathrm{~b}$ ), population means and standard deviations were unchanged (when rounded to two significant figures), suggesting that the recorded deposition and erosion did not influence local slope. See Supplementary Material (Figure $\mathrm{S} 37$ and $\mathrm{S} 38$ ) for data from experimental repeats. 


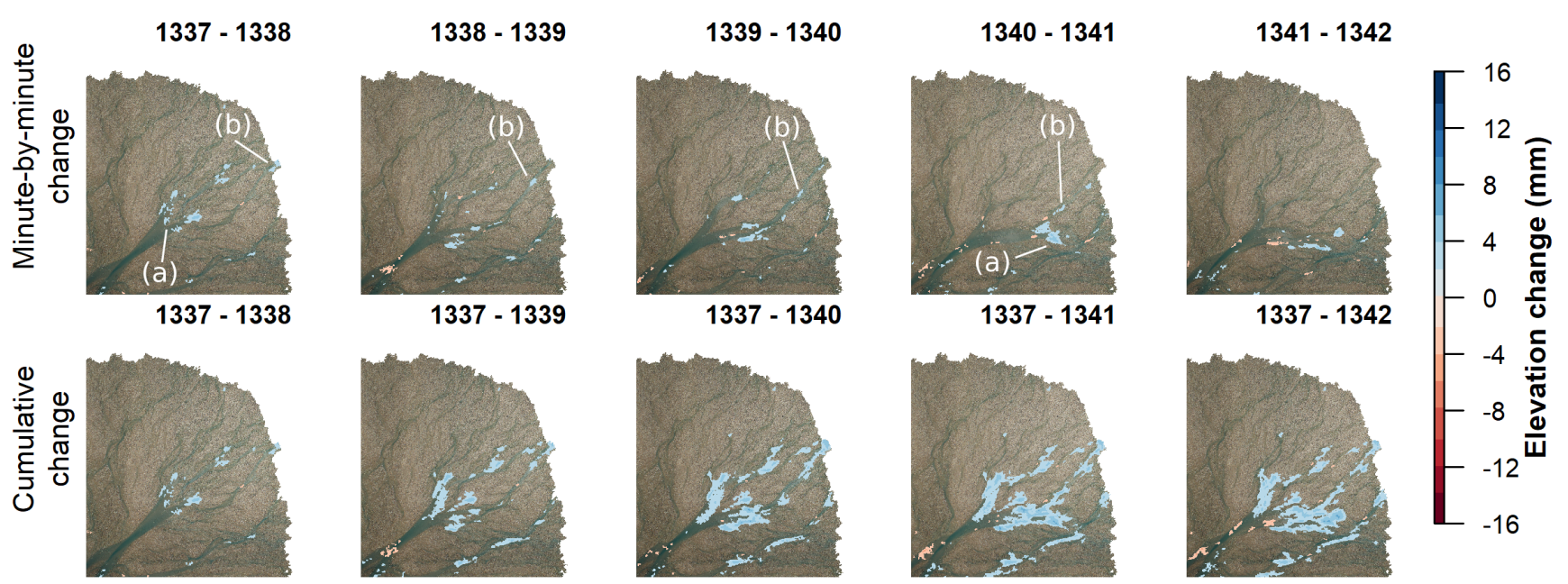

Figure 10: DEMs of difference (DoDs) for the five minutes after an avulsion at 13:37. Upper panel: minute-to-minute topographic change. Lower panel: cumulative topographic change. (a) = deposition concentrated at bifurcations; (b) = short-lived back-filling, curtailed by minor avulsion on the lower fan.

The distribution of estimated depths across deposition and erosion patches varied from t 1 to t2, highlighting how deposition and erosion affected channel geometry. For t1 (Figure 12a), estimated depths for deposition and erosion patches were similar. Population means were 3.3 and $3.4 \mathrm{~mm}$ respectively (standard deviation $=0.77$ and $0.89 \mathrm{~mm}$ ).

Conversely, at 22 (after the observed deposition and erosion), estimated depth had shallowed in depositional patches and deepened in erosional patches (Figure 12b). Population means were 3.0 and $3.7 \mathrm{~mm}$ for deposition and erosion respectively (standard deviation $=0.68$ and $0.87 \mathrm{~mm}$ ). A Welch two-sample t-test shows that the shallowing of depositional patches and deepening of erosional patches were statistically significant $\left(p<2.2 \times 10^{-16}\right.$ in both cases). See Supplementary Material (Figure S 39 and S40) for plots from experimental repeats. We also note that our estimates are an index of depth that is suitable for comparing depths in the same experiment but not as a measure of absolute depth.

Estimated channel widths in deposition and erosion patches also varied between $\mathrm{t} 1$ and $\mathrm{t} 2$, again demonstrating the influence of deposition and erosion on channel geometry. At t1 (Figure $13 \mathrm{a}$ ), channel widths were similar in both depositional and erosional patches. Population means were 95 and $100 \mathrm{~mm}$ respectively (standard deviation $=76$ and $64 \mathrm{~mm}$ ).

At t2, however, channels had widened in depositional patches and narrowed in erosional patches (Figure 13p). Population means were 110 and $79 \mathrm{~mm}$ for deposition and erosion respectively (standard deviation $=78$ and $58 \mathrm{~mm}$ ). A Welch two-sample t-test shows that the widening of depositional patches and narrowing of erosional patches were statistically significant $\left(p=1.3 \times 10^{-6}\right.$ and $p=7.5 \times 10^{-11}$ respectively). See Supplementary Material (Figures $\mathrm{S} 41$ and $\mathrm{S} 42$ ) for plots from experimental repeats. Again, these estimates of channel width are estimates rather than absolute measures, as they were made along arcuate cross-fan profiles

and are therefore perpendicular to the fan radius rather than to flow. 

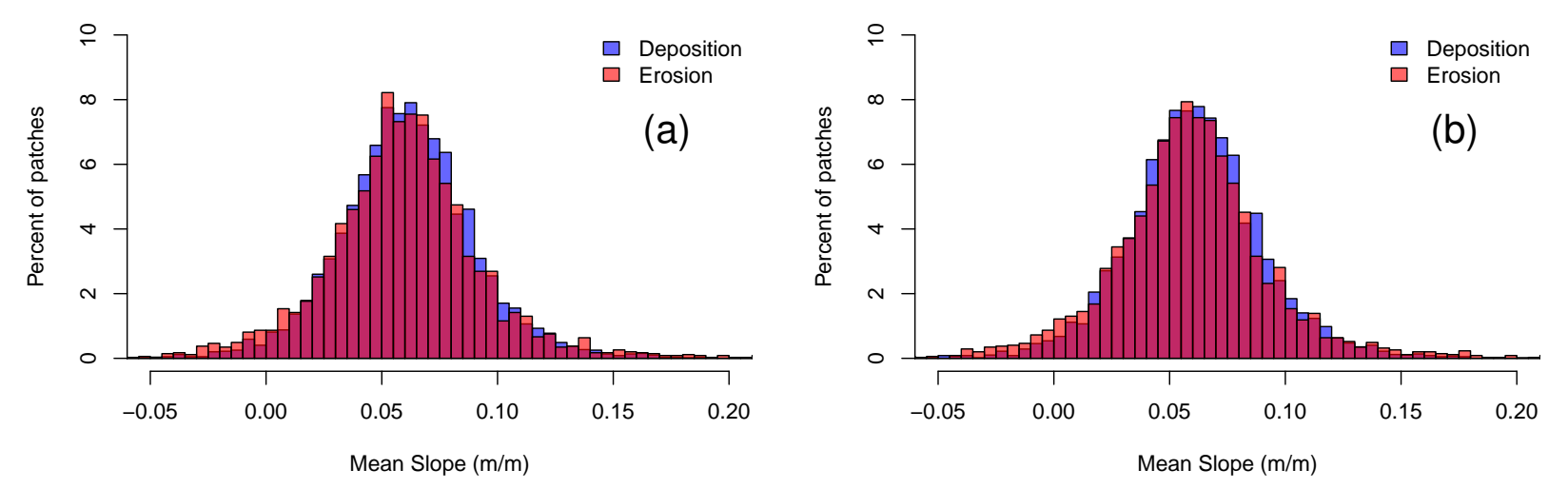

Figure 11: Distribution of down-fan slope through patches of deposition and erosion. Patches smaller than $5 \mathrm{~cm}^{2}$ are omitted. (a) $=\mathrm{t} 1$; (b) $=\mathrm{t} 2$. The population means and standard deviations were unchanged by the erosion/deposition recorded between $\mathrm{t} 1$ and $\mathrm{t} 2$. The dark magenta bars indicate where the two histograms overlap.

\section{Discussion}

Our principal aims were 1) to characterize temporal changes in flow distribution (i.e. periodicity of the autogenic cycle), 2) to characterize the topographic change following major avulsions or the onset of channelized flow, and 3) to understand the linkages between local topographic change and flow pattern adjustment. Our results showed that 1) channel reorganization events and periods of channelized flow were aperiodic; 2) there was minimal evidence of back-filling or upstream-moving deposition following avulsion or the onset of channelized flow, as other authors have suggested; 3 ) contrary to our expectations based on previous studies, local slope was not significantly lower in patches of deposition, although deposition did cause significant channel shallowing and widening.

\subsection{Periodicity of avulsion and channelized flow}

Avulsion, divergence and convergence events during the experiment were rapid. Those we observed manually had durations of 1-6 minutes. This accords with field studies of avulsion on fans, which have suggested or observed that avulsion events generally take place during a single flood event (Bernal et al., 2012; Field, 2001; Fuller, 2012; Kesel and Lowe, 1987; Mack et al. 2008; Pearthree et al., 2004; Wells and Dorr, 1987).

To ascertain how periodic the autogenic avulsion cycle was in our experiment, we applied the Kim and Jo (2016) burstiness parameter $A_{n}$ to both manually and automatically identified chan- 

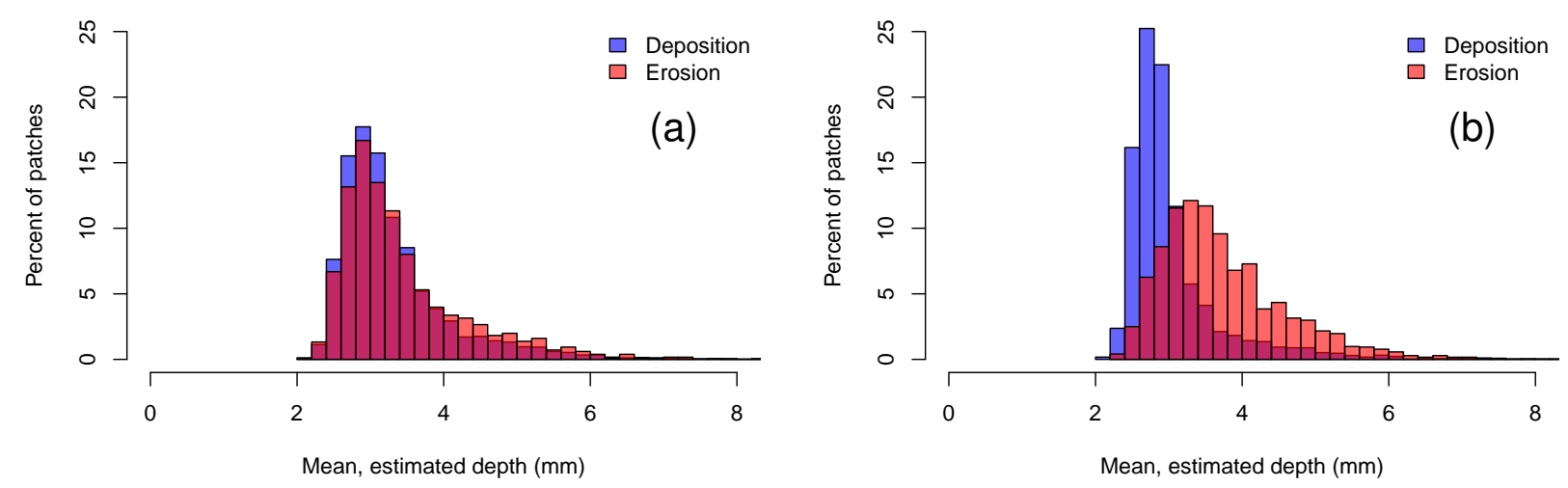

Figure 12: Mean estimated flow depths at $\mathrm{t} 1$ (a) and $\mathrm{t} 2$ (b), for each patch of deposition or erosion in the DoDs. Patches smaller than $5 \mathrm{~cm}^{2}$ were removed. Between $\mathrm{t} 1$ and $\mathrm{t} 2$, channels shallowed at depositional patches and deepened at erosional patches.

nel reorganization events, and to the onset of channelized flow periods. For all cases, $A_{n}$ was close to zero, suggesting that the timing of reorganization events and periods of channelized flow was random, and thus aperiodic. In addition, the interval between events appeared to be unrelated to fan radius. These results are a little surprising: other alluvial fan and delta experiments exhibited more periodic autogenic cycles (e.g. Carlson et al., 2018, Figure 1; Hamilton et al., 2013, Figures 11-13; Reitz et al., 2010, Figure 2). The aperiodicity of our experiment may reflect the paucity of back-filling in Figures 8,9, as we discuss below.

The causes of avulsion are often subdivided into two categories: "setup" and "trigger" (Jones and Schumm, 1999; Slingerland and Smith, 2004). Setup refers to processes such as channel filling or aggradation, that reduce channel capacity and thereby prime the channel for avulsion. Triggers are typically flood events that generate overbank flow, leading to avulsion. Theoretical work has indicated that the time between avulsions could be predicted from the efficiency of the setup: that is, from the length of time required for the channel to aggrade to one channel-depth (Jerolmack and Mohrig, 2007). More specifically for fans, Reitz et al. (2010) proposed that the average time between avulsions could be predicted from the time to back-fill the channel over the length of the fan radius. These theories imply that, if water and sediment supply are constant, the avulsion cycle on fans should be periodic, and the time between avulsions should scale with fan radius.

However, the notion that the time between avulsions can be predicted from the time required to back-fill the channel implicitly assumes that all sediment supplied to the fan is transported to the fan-toe, to contribute to back-filling. In a widely graded mixture such as ours, it is unlikely that all grains in the largest classes are transported to the fan-toe. In addition, when sediment supply is high (as in our experiment), channels may be capacity limited, meaning that much of the supplied material is not transported to the fan-toe. These factors may explain the lack of 

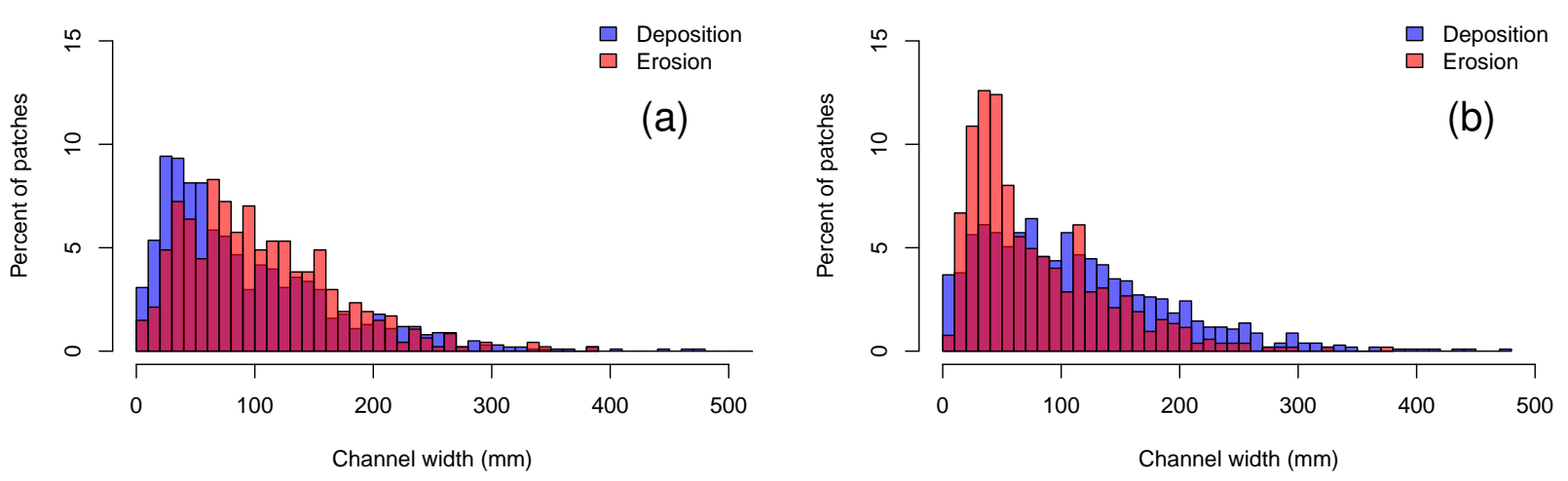

Figure 13: Distribution of channel widths at deposition and erosion patches. Data from t1 (a) and t2 (b). Between $\mathrm{t} 1$ and $\mathrm{t} 2$, channels widened at deposition patches and narrowed at erosion patches.

back-filling in our experiment, and therefore the aperiodic nature of the autogenic cycle and the fact that the intervals between channel reorganization events were unrelated to fan radius. We further consider the paucity of back-filling in section 4.2 .

The avulsions detected by our automated method were apical avulsions. Using criteria for avulsion size proposed by Densmore et al. (2019), we estimated that avulsion size ranged from $0.12-0.45$ with a mean of 0.26 (where 0 represents no avulsion, and 1 represents an apical avulsion from one fan boundary to the other). Although these were apical avulsions, the opening angles were relatively small, constraining the avulsion "size" as measured by this metric. Although we are not aware of field data relating to avulsion angles on fluvial fans, a recent study of 176 debris flows on fans in British Columbia, Canada found that most debris flow avulsions had an opening angle of less than half the fan opening angle, in similarity to the avulsions in our experiment (Zubrycky, 2020).

With respect to the automated method for identifying channel reorganization events, there were some issues with our method of comparing flow maps and quantifying the area newly occupied or abandoned by flow. The method worked well for identifying avulsion (identifying 8/9 of the manually observed avulsions), but less so for divergence (5/13) and convergence (6/18) events (Table S6). There are three potential causes for this discrepancy. Firstly, we may have selected inappropriate area thresholds to identify divergence and convergence. The upper threshold (10.5\% of the fan area) matched our criteria for avulsion, but for the lower threshold ( $8 \%)$, we tried a range of other thresholds for which the success rate was even lower. So, we consider this first explanation unlikely. A second explanation is that the durations of divergence and convergence events are more variable (Table S6), so that not all events are captured with the three-minute lag. Table $\mathrm{S6}$ shows that most divergence and convergence events that were successfully captured did have a duration of three minutes. A final possible explanation is that the "class" of events that we manually identified as divergence (or convergence) do not in fact 
share similar values of new or abandoned flow area. This highlights the subjectivity of manual classification, where one may identify a suite of events as having similar character, only to find that they are quite different when the variables of interest are quantified.

\subsection{Topographic change}

Conceptual models of back-filling on fans suggest that, following avulsion or the onset of channelized flow, deposition should be concentrated toward the fan-toe and should then propagate upstream (e.g. Reitz and Jerolmack, 2012; Schumm et al., 1987). However, despite tracking deposition locations with high-frequency topographic data, we saw little evidence of an up-fan shift in depositional loci following avulsion or the onset of channelized flow (in our first experimental repeat, e.g. Figure 8). We did observe minor back-filling at the fan's distal margin, but it generally lasted for only a few minutes before sediment supply was diverted by channel pattern change further up-fan. We therefore infer that back-filling played a minimal role in our experiment.

Previous work has suggested that back-filling on fans is triggered by a down-fan reduction in slope (e.g. Reitz and Jerolmack, 2012; Schumm et al., 1987). We used the DoDs to test the influence of local slope on depositional patterns, and found no significant difference between the slopes of erosional and depositional patches in our experiment. This result was consistent when measuring slope before and after the DoD ( $t 1$ and t2; see Figure 11), when comparing different repeats, when using longer intervals (two or five minutes) to calculate the $D o D$, and when calculating slope along flow lines rather than radial profiles (Figure S43- S45, Supplementary Material). These results suggest that local slope was not a major influence on depositional location. Nevertheless, a reduction in slope must trigger deposition at the very toe of the fan, due to the associated reduction in competence. This small region is not represented in our data, as we limited our analysis to areas that built to $>6 \mathrm{~mm}$ above the initial surface.

Given that we found little evidence for local slope as a driver of deposition, we examined local channel geometry to ascertain if differences in depth (and hence shear stress) may be responsible for the depositional patterns observed. At t1, the populations of local slopes, flow depths and widths were similar for deposition and erosion patches (Figures 11, 12 and 13, panel a). Shear stress on the bed can be approximated as $\tau_{b}=\rho g H S$ (where $\rho=$ fluid density, $g=$ gravitational acceleration, $H=$ hydraulic radius, a function of flow depth and width, and $S=$ channel slope). It follows that, if local changes in channel geometry were responsible for the observed depositional patterns, we would expect depositional patches to have lower shear stress than erosional patches, at t1; a lower shear stress would trigger distrainment and deposition. However, we estimate $\tau_{b}=1.9 \mathrm{~N} \mathrm{~m}^{-2}$ for both depositional and erosional patches (using mean estimates of local flow depth, width and slope for each population). This similarity in estimated shear stress suggests that local reductions in shear stress, due to local changes in channel 
geometry, are not a reasonable explanation for the depositional patterns observed.

At t2, channels had shallowed in depositional patches and deepened in erosional patches (Figure 12p). Contemporaneously, channels had widened in depositional patches and narrowed in erosional patches (Figure 13p). These adjustments were statistically significant, and were observed in all experimental repeats. We estimate that, at $\mathrm{t} 2$, local shear stress had decreased to $1.7 \mathrm{~N} \mathrm{~m}^{-2}$ in depositional patches, and increased to $2.0 \mathrm{~N} \mathrm{~m}^{-2}$ in erosional patches. These estimates suggest that deposition generally reduced shear stress through widening and shallowing channels, which may in turn have encouraged further deposition through positive feedbacks. The reverse is, to a lesser degree, true for erosion.

\subsection{Disrupting the avulsion cycle}

As described in section 4.2, in-channel deposition initiated shallowing and widening (Figures 12 and 13. Channel widening due to deposition may trigger local adjustments to flow pattern, such as lateral migration, bifurcation, flow redistribution between channel threads, or minor avulsion. These adjustments divert sediment transport away from the active fan-toe lobe, thereby disrupting back-filling from that lobe. The progress of the autogenic avulsion cycle is thus interrupted, and as a result of many such interruptions, avulsion occurrence becomes aperiodic. As discussed in section 4.2, the initial hydraulic conditions in erosional and depositional patches were not significantly different. This indicates that local changes to hydraulic conditions, while important, may not be the main control on depositional patterns. Rather, deposition may begin in response to the material supplied to a channel thread, and to random variations therein. With a continuous supply of sediment at a concentration of almost $2 \%$ by volume, the fan was capacity limited: the pre-deposition (t1) shear stress of approximately $1.9 \mathrm{~N} \mathrm{~m}^{-2}$ was $\sim 4$ times the entrainment threshold for the $D_{50}$, and yet deposition occurred at any distance down-fan. We thus infer that in-channel deposition was likely throughout the experiment, but there are two phenomena which may have enhanced the likelihood of in-channel deposition: 1) small local peaks in the sediment flux to a particular channel thread at a particular distance down-fan, and

2) the lower mobility of larger grains in our sediment mixture.

Although we did not directly measure the down-fan sediment flux, we identified local peaks using the DoDs. Some DoD sequences (e.g. Figure 9) showed relatively large patches of deposition that migrated down-fan, dispersing as they moved. The sediment supply to the experiment was constant, so these sediment pulses likely arise from local erosion (e.g. bank failure). In some cases, such sediment pulses caused sufficient deposition and shallowing to plug a channel and precipitate avulsion; Figure 14 shows one example of this process.

Little is known about the contribution of bank erosion to the sediment budget on alluvial fans. However, rates and volumes of bank erosion have been well-studied in other stream types; reported contributions of bank erosion to suspended sediment budgets range from $10 \%$ to $>90 \%$ 


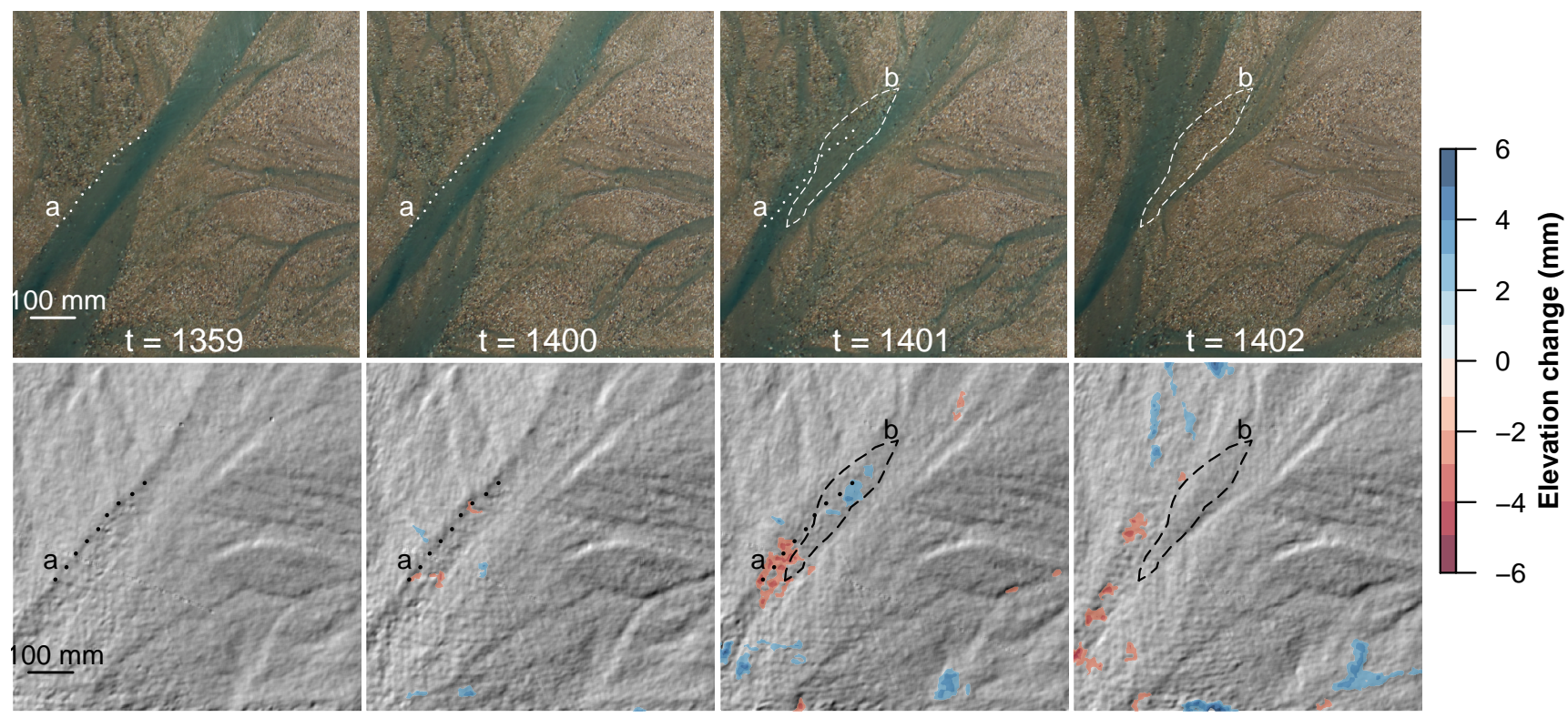

Figure 14: Orthophotos and hillshaded DEMs (cropped to the fan-head) showing the influence of local sediment pulses on fan-channels. Between $t=1359$ and $t=1401$, the left bank (a) and bed eroded, encouraging in-channel deposition just downstream. At $t=1401$, this sediment had formed a sheet-like deposit (b), which shallowed and widened the original channel and formed a bifurcation. By $t=1402$, all flow had collected into the left branch of the bifurcation, causing a large-scale avulsion further down-fan.

610 (e.g. Longoni et al., 2016; Rinaldi and Darby, 2007; Cashman et al., 2018). Sediment generated by bank erosion may be directly entrained into the flow or deposited on the bed (Grissinger et al., 1991; Shu et al., 2019). The volume and size of material input to the channel will control whether the material aggrades the bed or is transported downstream (Rinaldi and Darby, 2007; Swartenbroekx et al., 2010). Further studies of on-fan sediment budgets (for instance, of cut-and-fill patterns revealed in repeat DoDs) could help to decipher the relation between bank erosion and channel sedimentation on natural fans.

A second likely trigger for in-channel deposition was the low mobility of larger grains in our sediment mixture. Recent work shows that large grains can have a dominant influence on morphodynamics (e.g. MacKenzie and Eaton, 2017; MacKenzie et al., 2018; Williams et al., 2019). In our experiment, the largest $1.4 \%$ of grains (sizes $>2.8 \mathrm{~mm}$ ) were mobile in the feeder channel, but often came to rest on the upper fan. If these relatively large grains deposited in a channel, the high and continuous sediment supply meant that they often triggered further deposition. As mentioned previously, in-channel deposition tended to cause flow widening, often leading to larger flow pattern adjustment. An example of a large-grain accumulation which triggered flow pattern adjustment is shown in Figure 15. Therefore, although large grains have a stabilizing role in streams with low sediment supply or in laterally confined settings, in our experiment accumulations of large grains tended to trigger instability and flow pattern adjustment. This difference likely reflects the high sediment supply and laterally unconfined channels in our experiment. 


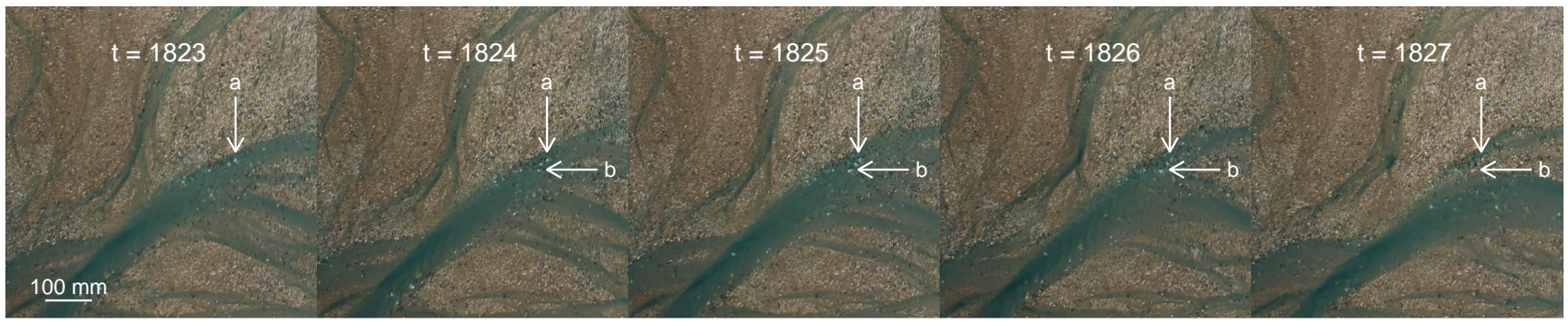

Figure 15: Sequential orthophotos (cropped to the fan-head) demonstrating the influence of large grains on fan-channels. At $t=1823$, two large white grains (around $6 \mathrm{~mm}$ ) were in place (a). At $t=1824$, a third large grain came to rest in their vicinity (b). At $t=1825$, an additional grain became anchored at (b). The area shallowed at $t=1826$, and flow was diverted away from the accumulation at $t=1827$.

Flow widening and adjustment around depositional patches, or around accumulations of larger grains, may thus explain why our experiment did not exhibit a more periodic autogenic avulsion cycle. While the geometric standard deviation of our sediment is comparable to that of previous studies (e.g. Carlson et al., 2018; Hamilton et al., 2013; Reitz et al., 2010), the relative size of the largest grain $\left(D_{\max } / D_{50}\right)$ was much greater in our experiments. We believe that this coarse tail (grains $>2.8 \mathrm{~mm}$ ) exerted a disproportionately large influence on fan morphodynamics, through deposits of these large grains and the associated channel widening, flow pattern adjustment, and interruption of back-filling and the autogenic avulsion cycle.

The influence of sediment grading has implications for natural fans. Those with a widely graded supply are more prone to accumulations of larger grains and subsequent flow widening. Mixture grading may be particularly important in paraglacial fans, where the primary sediment source is often widely graded till (Ryder, 1971), or in volcanic settings, where lahars can supply boulders that are well beyond the competence of fluvial flows (Williams et al., 2019).

The impact of flow pattern adjustment (such as flow re-partitioning between channel threads) can vary depending on where the adjustment occurs. As we mentioned, in-channel deposition triggered flow widening and shallowing. On the lower fan, these small adjustments can initiate the minor avulsion of a channel thread (for instance, in Figure 7 at (f)). However, when such adjustment occurs on the upper fan, a major apical avulsion may be triggered (as in Figure 14; patterns of in-channel deposition prior to each avulsion are shown in Figure S46, Supplementary Material). In either case, deposition and a reduction in channel capacity is the cause of the avulsion, but the severity and size of the avulsion is determine by where the channel is breached.

Our finding that channel filling may trigger avulsions that are unpredictable in space and time supports recent observations from debris-flow fans. Field observations indicate that channel plugging can be a trigger for stochastic avulsion of debris flows on fans (de Haas et al., 2019). Similarly, experimental evidence shows that small debris flows may plug a channel so that subsequent larger flows undergo avulsion (de Haas, Kruijt and Densmore, 2018). Moreover, debris flow composition (grain size distribution) can increase the likelihood of channel plugging and 
avulsion (de Haas, Densmore, Stoffel, Suwa, Imaizumi, Ballesteros-Cánovas and Wasklewicz, 2018). This concurs with our observations on a fluvial fan, despite different flow conditions and

sediment concentration.

To trigger avulsion, flood volume must exceed the channel capacity, inciting overbank flow (Jones and Schumm, 1999; Slingerland and Smith, 2004). In the "classic" model of the autogenic avulsion cycle, channel capacity decreases through slope-induced back-filling from the fan-toe. However, our data show that, at least when sediment supply is high and the GSD is widely graded, deposition at any distance down-fan can locally reduce channel capacity and initiate avulsion. Consequently, the location of the avulsion node (and avulsion timing) is likely related to the volume and GSD of material being transported down the fan, as these factors can induce deposition and a subsequent reduction in channel capacity. This accords with field observations that avulsion tends to occur in aggrading zones on fans (Field, 2001).

\section{Conclusion}

Using our high-frequency, high-resolution DEMs and orthophotos, we tracked the co-evolution of flow patterns and topography in an alluvial fan experiment with constant flow and sediment feed and widely graded sediment. These data allowed us to monitor the frequency of avulsion and channelized flow periods. We used DEMs of difference to examine patterns of deposition and erosion, and compared channel geometry in erosional and depositional patches.

Major avulsions and other channel reorganization events in our experiment were rapid, lasting three minutes on average. These events, as well as periods of channelized flow, occurred aperiodically. After avulsion or the onset of channelized flow, we saw little evidence of slope-induced back-filling. In fact, local down-fan slope was not significantly different between patches of deposition and erosion, implying that local slope was not a trigger for deposition. However, a key finding was that in-channel deposition generally triggered flow widening and shallowing, significantly altering flow patterns on the fan.

These findings contrast some alluvial fan experimental studies which proposed that avulsion occurs in response to channel back-filling triggered by a down-fan reduction in slope. One main reason for the contrasting behavior of our experiment may be our widely graded sediment; coarser fractions move down the fan more slowly. Consequently, relatively coarse grains tend to deposit up-fan, initiating flow expansion and shallowing. Similarly, peaks in the local sediment flux may trigger in-channel deposition, leading to flow widening and shallowing. Whatever the cause of local deposition, the associated reduction in capacity primes the channel for avulsion or minor flow adjustments. Minor flow adjustments redirect the sediment supply to the fan-toe, interrupting any back-filling and thereby disrupting the "autogenic avulsion cycle". As we observed, avulsion occurrence thus becomes aperiodic, and difficult to predict. 
Instead of being triggered by back-filling, avulsion could be triggered by local channel filling in response to accumulations of large grains or peaks in the local sediment flux. On natural

fans where avulsion hazards pose a risk to public safety, we therefore encourage frequent topographic monitoring to identify sites that are actively aggrading and may become the loci of future avulsions.

Finally, our high-frequency, high-resolution data allowed us to monitor fan and fan-channel evolution in unprecedented detail. We stress that, in geomorphology, we must strive to collect data at a higher frequency than that of the process of interest. We therefore advocate for highfrequency topographic surveys where landscapes and forms are dynamic and rapidly evolving.

\section{Acknowledgments}

Experimental construction and equipment purchase were funded through an NSERC Discovery Grant to B. Eaton. Thanks to Lucy MacKenzie, Mike Church, Tjalling de Haas, and Lucy Clarke, for in-depth reviews which greatly improved the clarity and quality of our manuscript.

\section{References}

Ashworth, P. J., Best, J. L., Leddy, J. O. and Geehan, G. W. (1994), The physical modelling of braided rivers and deposition of fine-grained sediment, in M. J. Kirkby, ed., 'Process models and theoretical geomorphology', John Wiley and Sons, pp. 115-139.

Beaumont, P. (1972), 'Alluvial fans along the foothills of the Elburz Mountains, Iran', Palaeogeography, Palaeoclimatology, Palaeoecology 12(4), 251 - 273.

Beaumont, P. and Oberlander, T. (1971), 'Observations on stream discharge and competence at Mosaic Canyon, Death Valley, California', Geological Society of America Bulletin 82(6), 1695-1698.

Bernal, C., Christophoul, F., Soula, J.-C., Darrozes, J., Bourrel, L., Laraque, A., Burgos, J., De Berc, S. B. and Baby, P. (2012), 'Gradual diversions of the Rio Pastaza in the Ecuadorian piedmont of the Andes from 1906 to 2008: role of tectonics, alluvial fan aggradation, and ENSO events', International Journal of Earth Sciences 101(7), 1913-1928.

Blair, T. C. and McPherson, J. G. (1994), 'Alluvial fans and their natural distinction from rivers based on morphology, hydraulic processes, sedimentary processes, and facies assemblages', Journal of sedimentary research 64(3a), 450-489. 
Blissenbach, E. (1952), 'Relation of surface angle distribution to particle size distribution on alluvial fans [Arizona]', Journal of Sedimentary Research 22(1), 25-28.

Booker, W. H. and Eaton, B. C. (2020), 'Stabilising large grains in self-forming steep channels', Earth Surface Dynamics 8(1), 51-67.

Bryant, M., Falk, P. and Paola, C. (1995), 'Experimental study of avulsion frequency and rate of deposition', Geology 23(4), 365-368.

Bull, W. B. (1977), 'The alluvial-fan environment', Progress in Physical Geography: Earth and Environment 1(2), 222-270.

Carlson, B., Piliouras, A., Muto, T. and Kim, W. (2018), 'Control of basin water depth on channel morphology and autogenic timescales in deltaic systems', Journal of Sedimentary Research 88(9), 1026-1039.

Cashman, M. J., Gellis, A., Sanisaca, L. G., Noe, G. B., Cogliandro, V. and Baker, A. (2018), 'Bank-derived material dominates fluvial sediment in a suburban Chesapeake Bay watershed', River Research and Applications 34(8), 1032-1044.

Chakraborty, T., Kar, R., Ghosh, P. and Basu, S. (2010), 'Kosi megafan: Historical records, geomorphology and the recent avulsion of the Kosi River', Quaternary International 227(2), 143160.

Clarke, L., Quine, T. A. and Nicholas, A. (2010), 'An experimental investigation of autogenic behaviour during alluvial fan evolution', Geomorphology 115(3), 278-285.

Davidson, S. K., Hartley, A. J., Weissmann, G. S., Nichols, G. J. and Scuderi, L. A. (2013), 'Geomorphic elements on modern distributive fluvial systems', Geomorphology 180-181, 82 -95 .

Davies, T. R. and Korup, O. (2007), 'Persistent alluvial fanhead trenching resulting from large, infrequent sediment inputs', Earth Surface Processes and Landforms 32(5), 725-742.

Davies, T. R. and McSaveney, M. J. (2008), 'Principles of sustainable development on fans', Journal of Hydrology (New Zealand) pp. 43-65.

Davies, T. R., McSaveney, M. J. and Clarkson, P. J. (2003), 'Anthropic aggradation of the Waiho River, Westland, New Zealand: microscale modelling', Earth Surface Processes and Landforms: The Journal of the British Geomorphological Research Group 28(2), 209-218.

de Haas, T., Densmore, A., den Hond, T. and Cox, N. (2019), 'Fan-Surface Evidence for DebrisFlow Avulsion Controls and Probabilities, Saline Valley, California', Journal of Geophysical Research: Earth Surface 124(5), 1118-1138. 
de Haas, T., Densmore, A., Stoffel, M., Suwa, H., Imaizumi, F., Ballesteros-Cánovas, J. and

Wasklewicz, T. (2018), 'Avulsions and the spatio-temporal evolution of debris-flow fans', Earth-Science Reviews 177, 53-75.

de Haas, T., Kruijt, A. and Densmore, A. (2018), 'Effects of debris-flow magnitude-frequency distribution on avulsions and fan development', Earth Surface Processes and Landforms 43(13), 2779-2793.

de Haas, T., Van Den Berg, W., Braat, L. and Kleinhans, M. G. (2016), 'Autogenic avulsion, channelization and backfilling dynamics of debris-flow fans', Sedimentology 63(6), 15961619.

Delorme, P., Devauchelle, O., Barrier, L. and Métivier, F. (2018), 'Growth and shape of a laboratory alluvial fan', Physical Review E 98(1), 012907.

Delorme, P., Voller, V., Paola, C., Devauchelle, O., Lajeunesse, É., BARRIER, L. and Métivier, F. (2017), 'Self-similar growth of a bimodal laboratory fan', Earth Surface Dynamics 5(2), 239 $-252$.

Denny, C. S. (1965), Alluvial fans in the Death Valley region, California and Nevada, Geological Survey Professional Paper 466, US Government Printing Office.

Densmore, A. L., de Haas, T., McArdell, B. W. and Schuerch, P. (2019), Making sense of avulsions on debris-flow fans, in 'Association of Environmental and Engineering Geologists; special publication 28', Colorado School of Mines. Arthur Lakes Library.

Eckis, R. (1928), 'Alluvial fans of the Cucamonga district, southern California', The Journal of Geology 36(3), 224-247.

775 Field, J. (2001), 'Channel avulsion on alluvial fans in southern Arizona', Geomorphology 37(12), 93-104.

Fonstad, M. A., Dietrich, J. T., Courville, B. C., Jensen, J. L. and Carbonneau, P. E. (2013), 'Topographic structure from motion: a new development in photogrammetric measurement', Earth Surface Processes and Landforms 38(4), 421-430.

Fuller, J. (2012), Evaluation of Avulsion Potential on Active Alluvial Fans in Central and Western Arizona, Technical Report CR-12-D, Arizona Geological Survey Contributed Report.

Grissinger, E. H., Bowie, A. J. and Murphey, J. B. (1991), Goodwin Creek bank instability and sediment yield, in 'Proceedings: Fifth Federal Interagency Sedimentation Conference', 1821 March, Las Vegas, NV, pp. 32-39.

785 Guerit, L., Métivier, F., Devauchelle, O., Lajeunesse, E. and Barrier, L. (2014), 'Laboratory alluvial fans in one dimension', Physical Review E 90(2), 022203. 
Hamilton, P. B., Strom, K. and Hoyal, D. C. (2013), 'Autogenic incision-backfilling cycles and lobe formation during the growth of alluvial fans with supercritical distributaries', Sedimentology 60(6), 1498-1525.

MacKenzie, L. G. and Eaton, B. C. (2017), 'Large grains matter: contrasting bed stability and
morphodynamics during two nearly identical experiments', Earth Surface Processes and

MacKenzie, L. G. and Eaton, B. C. (2017), 'Large grains matter: contrasting bed stability and
morphodynamics during two nearly identical experiments', Earth Surface Processes and Landforms 42(8), 1287-1295.

Hooke, R. L. (1967), 'Processes on arid-region alluvial fans', The Journal of Geology 75(4), 438-460.

Hooke, R. L. (1968a), 'Model geology: prototype and laboratory streams: discussion', Geological Society of America Bulletin 79(3), 391-394.

Hooke, R. L. (1968b), 'Steady-state relationships on arid-region alluvial fans in closed basins', American Journal of Science 266(8), 609-629.

Hooke, R. L. and Rohrer, W. L. (1979), 'Geometry of alluvial fans: Effect of discharge and sediment size', Earth Surface Processes 4(2), 147-166.

Jerolmack, D. J. and Mohrig, D. (2007), 'Conditions for branching in depositional rivers', Geology 35(5), 463-466.

Jones, L. and Schumm, S. (1999), 'Causes of avulsion: an overview', Fluvial sedimentology VI 28, 171-178.

Kesel, R. H. and Lowe, D. R. (1987), 'Geomorphology and sedimentology of the Toro Amarillo alluvial fan in a humid tropical environment, Costa Rica', Geografiska Annaler: Series A, Physical Geography 69(1), 85-99.

Kim, E.-K. and Jo, H.-H. (2016), 'Measuring burstiness for finite event sequences', Physical Review E 94(3), 032311.

Korup, O. (2004), 'Landslide-induced river channel avulsions in mountain catchments of southwest New Zealand', Geomorphology 63(1-2), 57-80.

Longoni, L., Papini, M., Brambilla, D., Barazzetti, L., Roncoroni, F., Scaioni, M. and Ivanov, V. I. (2016), 'Monitoring riverbank erosion in mountain catchments using terrestrial laser scanning', Remote Sensing 8(3), 241.

Mack, G. H., Leeder, M. R. and Carothers-Durr, M. (2008), 'Modern flood deposition, erosion, and fan-channel avulsion on the semiarid Red Canyon and Palomas Canyon alluvial fans in the southern Rio Grande rift, New Mexico, USA', Journal of Sedimentary Research 78(7), 432-442. 
Mackenzie, L. G., Eaton, B. C. and Church, M. (2018), 'Breaking from the average: Why large grains matter in gravel-bed streams', Earth Surface Processes and Landforms 43(15), 31903196.

Miller, K. L., Kim, W. and McElroy, B. (2019), 'Laboratory investigation on effects of flood intermittency on fan delta dynamics', Journal of Geophysical Research: Earth Surface 124(2), 383-399.

Parker, G. (1979), 'Hydraulic geometry of active gravel rivers.', Journal of the Hydraulics Division, ASCE 105(HY9, Proc. Paper, 14841), 1185-1201.

Pearthree, P. A., Klawon, J. E. and Lehman, T. W. (2004), Geomorphology and hydrology of an alluvial fan flood on Tiger Wash, Maricopa and La Paz Counties, west-central Arizona, Technical Report 04-02, Arizona Geological Survey.

Piliouras, A., Kim, W. and Carlson, B. (2017), 'Balancing aggradation and progradation on a vegetated delta: The importance of fluctuating discharge in depositional systems', Journal of Geophysical Research: Earth Surface 122(10), 1882-1900.

Pyrce, R. S. and Ashmore, P. E. (2003), 'The relation between particle path length distributions and channel morphology in gravel-bed streams: a synthesis', Geomorphology 56(1-2), 167187.

R Core Team (2019), R: A Language and Environment for Statistical Computing, R Foundation for Statistical Computing, Vienna, Austria.

Rahn, P. H. (1967), 'Sheetfloods, streamfloods, and the formation of pediments', Annals of the Association of American Geographers 57(3), 593-604.

Reitz, M. D. and Jerolmack, D. J. (2012), 'Experimental alluvial fan evolution: Channel dynamics, slope controls, and shoreline growth', Journal of Geophysical Research: Earth Surface 117(F2), F02021.

Reitz, M. D., Jerolmack, D. J. and Swenson, J. B. (2010), 'Flooding and flow path selection on alluvial fans and deltas', Geophysical Research Letters 37(6), L06401.

Rinaldi, M. and Darby, S. E. (2007), Modelling river-bank-erosion processes and mass failure mechanisms: progress towards fully coupled simulations, in $\mathrm{H}$. Habersack, H. Piégay and M. Rinaldi, eds, 'Gravel-Bed Rivers VI: From Process Understanding to River Restoration', Vol. 11 of Developments in Earth Surface Processes, Elsevier, pp. 213 - 239.

Ryder, J. M. (1971), 'The Stratigraphy and Morphology of Para-glacial Alluvial Fans in Southcentral British Columbia', Canadian Journal of Earth Sciences 8(2), 279-298.

Schlichting, H. and Gersten, K. (2016), Boundary-layer theory, Springer. 
Schumm, S. A., Mosley, M. P. and Weaver, W. (1987), Experimental fluvial geomorphology, John Wiley and Sons Inc., New York.

Shu, A., Duan, G., Rubinato, M., Tian, L., Wang, M. and Wang, S. (2019), 'An experimental study on mechanisms for sediment transformation due to riverbank collapse', Water 11(3), 529.

Sinha, R. (2009), 'The great avulsion of Kosi on 18 August 2008', Current Science pp. 429-433.

Slingerland, R. and Smith, N. D. (2004), 'River avulsions and their deposits', Annu. Rev. Earth Planet. Sci. 32, 257-285.

Swartenbroekx, C., Soares-Frazão, S., Staquet, R. and Zech, Y. (2010), 'Two-dimensional operator for bank failures induced by water-level rise in dam-break flows', Journal of Hydraulic Research 48(3), 302-314.

Van Dijk, M., Kleinhans, M. G., Postma, G. and Kraal, E. (2012), 'Contrasting morphodynamics in alluvial fans and fan deltas: effect of the downstream boundary', Sedimentology 59(7), 2125-2145.

Van Dijk, M., Postma, G. and Kleinhans, M. G. (2009), 'Autocyclic behaviour of fan deltas: an analogue experimental study', Sedimentology 56(5), 1569-1589.

Wells, N. A. and Dorr, J. A. (1987), 'Shifting of the Kosi river, northern India', Geology 15(3), 204-207.

Westoby, M. J., Brasington, J., Glasser, N. F., Hambrey, M. J. and Reynolds, J. M. (2012), "Structure-from-Motion' photogrammetry: A low-cost, effective tool for geoscience applications', Geomorphology 179, 300-314.

Whipple, K. X., Parker, G., Paola, C. and Mohrig, D. (1998), 'Channel dynamics, sediment transport, and the slope of alluvial fans: Experimental study', Journal of Geology 106(6), 677-693.

Williams, R., Reid, H. and Brierley, G. (2019), 'Stuck at the bar: larger-than-average grain lag deposits and the spectrum of particle mobility', Journal of Geophysical Research: Earth Surface 124(12), 2751-2756.

Woods, S. W., MacDonald, L. H. and Westbrook, C. J. (2006), 'Hydrologic interactions between an alluvial fan and a slope wetland in the central Rocky Mountains, USA', Wetlands 26(1), 230-243.

Yalin, M. S. (1971), Theory of hydraulic models, Macmillan International Higher Education.

Zubrycky, S. (2020), Spatial impact trends on debris flow fans in southwestern British Columbia, Master's thesis, University of British Columbia, Vancouver, Canada. 